\title{
Research on Control Technology of Jet and Rectifying Cone Combined Flow Field
}

\author{
Hongqing Lv, Lei Xu $\mathbb{D}$, Zhenqing Wang, and Xiaobin Zhang $\mathbb{D}$ \\ College of Aerospace and Civil Engineering, Harbin Engineering University, Harbin 150001, China \\ Correspondence should be addressed to Xiaobin Zhang; zhangxiaobin@hrbeu.edu.cn
}

Received 5 August 2020; Accepted 27 August 2020; Published 11 September 2020

Academic Editor: Li Yan

Copyright (c) 2020 Hongqing Lv et al. This is an open access article distributed under the Creative Commons Attribution License, which permits unrestricted use, distribution, and reproduction in any medium, provided the original work is properly cited.

\begin{abstract}
As an active flow field control technology, reverse jet and rectifier cone can significantly affect the flow field around the high-speed aircraft and reduce the drag and heat of high-speed aircraft to a certain extent. In this paper, the CFD numerical method is used to simulate and analyze the flow around the bluff body front rectifier cone and the reverse jet interference flow field. Further considering the combination of the two, the flow field structure around the bluff body under the combination of rectifying cone and reverse jet flow was simulated. Research shows, for the flow field of a single reverse jet, the pressure ratio of the reverse jet to the main flow has a significant effect on the drag reduction performance. With the change of the pressure ratio of the jet to the main flow, two modes of long jet and short jet will appear. The structure of the short jet modal flow field is relatively stable. However, with the increase of attack angle, the shear layer of free flow will attach to the shock wave and form hot spot, which is a great threat to high-speed aircraft. When the rectifier cone and the reverse jet are combined, within a certain angle of attack, the wall will not form a reattachment shock wave. The area behind the bow shock and in front of the aircraft head is a free-state zone, which has a good cooling effect on the aircraft head. At the same time, the static pressure on the wall is reduced, which has a very good drag reduction effect.
\end{abstract}

\section{Introduction}

The high-sonic vehicle is the main direction of the development of the world's aerospace industry in the 21st century. It has the characteristics of fast flight speed, short-reaction time, and strong penetration ability [1]. The hypersonic aircraft faces severe shock interference when flying, and the structure of the flow field is complex. The passivated front edge of the aircraft forms a bow shock wave composed of a normal shock wave and an oblique shock wave. The contribution rate of shock wave resistance in the resistance reaches even more than fifty percent $[2,3]$. The complicated shock wave interference flow field not only seriously affects the aerodynamic characteristics of the aircraft but also consumes more fuel under the same flight range, which brings additional fuel load burden to the aircraft. The more serious problem is that the increase of shock wave resistance causes obvious local airflow stagnation of the aircraft. Under the strong compression of the shock wave at the front end of the aircraft, due to the conservation of energy, the mechani- cal kinetic energy is transformed into internal energy. The increase in gas temperature will produce radiation and convection heating effects on the wall, causing serious aerodynamic heating problems to the aircraft, and posing a threat to the structural safety of the aircraft.

In order to optimize the aerodynamic environment and aerodynamic performance of the aircraft, increase the fuel consumption ratio of the voyage, reduce the aerodynamic heating level, and adopt appropriate resistance control technology to reduce the flight resistance of the aircraft is the key to solving the above problems [4]. Boundary layer control technology, energy deposition technology, shape control drag reduction technology, and reverse jet flow technology are currently several common drag reduction technologies. As a type of active flow control technology, reverse jet flow has always received the attention of researchers in the industry. Reverse jet drag reduction is an additional interference drag reduction technology. Its essence is to change the shock wave structure of the head of the aircraft through additional disturbances, so as to achieve the purpose of reducing the 


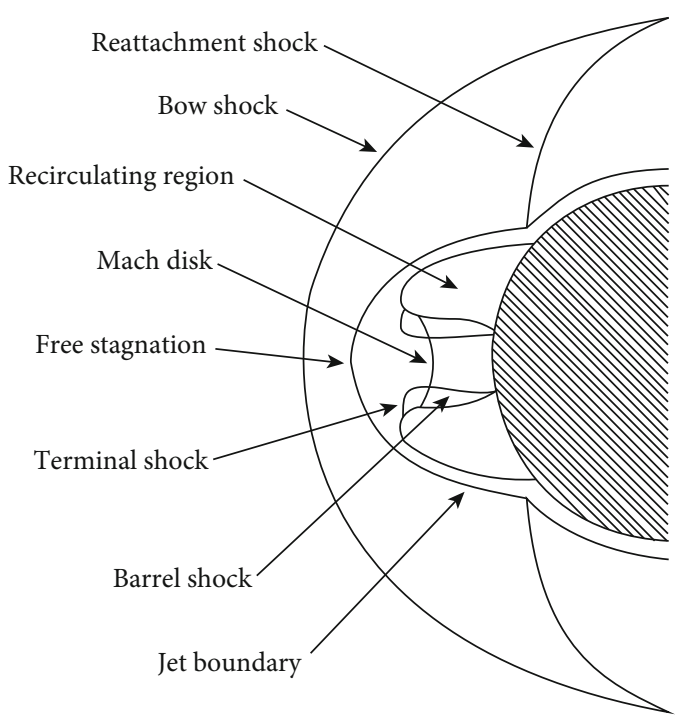

(a) Jet interference flow field

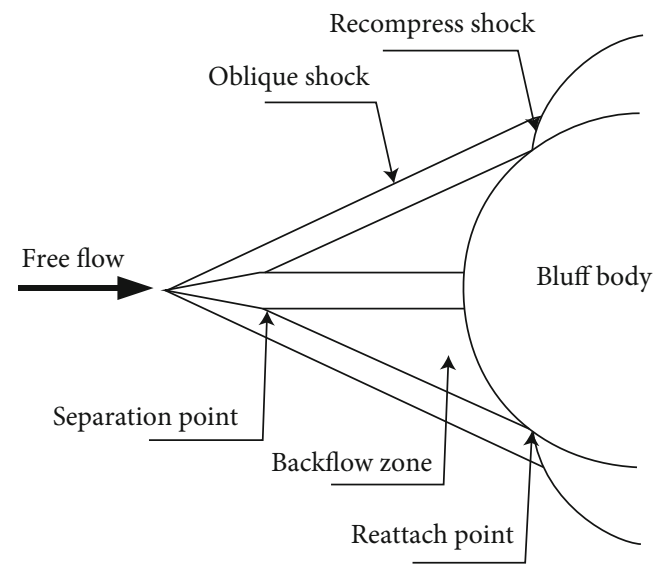

(b) Bluff body prerectifier cone

FIGURE 1: Schematic diagram of the drag reduction technology structure.

shock resistance to a certain extent. The reverse jet flow interference flow field structure is shown in Figure 1(a). Front rectifier cone drag reduction technology is a type of shape control drag reduction technology. In the 1950s, the American Langley Research Center test confirmed that installing a rod on the front end of the blunt body can reduce the resistance of the rotating body [5]. As shown in Figure 1(b), the basic principle is that a needle-like rectifying cone is preset at the front end of the bluff body. The rectifying cone can destroy the original shock wave structure and form before the airflow reaches the surface of the bluff body. A relatively weak shock wave subsequently forms a low-pressure recirculation zone in the head region. The presence of a rectifying cone changes the flow field structure and shock wave intensity, thereby reducing drag and aerodynamic heating effects.

Research on the technology of drag reduction and heat reduction of high-speed aircraft has very important significance both in theory and practice. Research on this field began in the 1960s; Warren experimentally studied the influence of jet pressure on the flow field pressure and ambient temperature [6] and proved that cooling the high-pressure gas jet can change the flow field structure and achieve the effect of drag reduction and heat reduction. Based on the detailed study of the interference flow field structure between the mainstream and the cold air jet, Finley further studied the stability of the interference flow field. It is believed that the ratio of the total pressure of the jet to the main pressure determines whether the flow field can obtain a stable interference structure [7]. In the 1990s, Japanese scientists began to study the reverse jet flow drag reduction and heat protection through wind tunnel tests and numerical methods and obtained a series of research results [8-12]. Formin used arc heating nitrogen to reverse the jet flow of the freeflowing frustum model with Mach numbers 2, 2.5, and 4, respectively. Both the experimental and numerical simulations obtained the two jet patterns observed during the cold jet flow. The long jet penetration mode and short jet penetration mode indicate that the flow state is mainly affected by the jet pressure, Mach number, and temperature, as well as the geometry of the object, the jet outlet, and the diameter of the blunt body [13]. The rectifying cone has been applied in hypersonic vehicles, such as the American Trident II ballistic missile and the Russian anti-missile system 51T6 long-range interceptor.

In recent years, China has gradually begun to study the problem of drag reduction and heat reduction of high-speed aircraft. Wang et al. numerically studied the thermal protection of the jet flow and analyzed the influence of the flow control parameters on the drag reduction and heat reduction effect of the jet flow [14-16]. Zhao and Jiang studied the experimental study and numerical simulation of the drag reduction mechanism of jet ions [17] and discussed the effects of plasma energy, ignition position, and shape on the drag reduction performance. Aiming at the research work of laser-plasma drag reduction in China, the existing problems at home and abroad are analyzed, and some suggestions for further research on the mechanism of laser-plasma drag reduction are proposed [18]. Zhou et al. studied a series of problems of reverse jet drag reduction of the shape of a supersonic blunt body and concluded that the effect of drag reduction and heat reduction is affected by the total pressure ratio of the jet, the flight angle of attack, and the size of the nozzle [1921]. Huang et al. gave a more detailed overview of the reverse jet and related technologies $[22,23]$ and studied the length of the rectifier cone and the pressure ratio of the reverse jet to reduce the resistance and heat resistance of the rectifier cone [24]. And the effect of porous reverse jet on drag and heat reduction of high-speed aircraft [25, 26]. Liu and others have studied that a reasonable jet temperature can improve the efficiency of drag reduction and heat reduction and can save space and weight more 
effectively [27]. Huang and Yao proposed the method of combining a pointed blunt body with a back-reverse jet, which has an impact on the drag and heat reduction of high-speed aircraft [28]..Wang and others applied the drag reduction effect of the reverse jet on the head directly to the aircraft, taking the ball head, single cone (including head), and double cone (that is, full bomb) of the typical double cone missile as the research object. The CFD method was used to fully simulate the internal and external flow of the reverse jet [29].

Throughout the existing literature, a single reverse jet can indeed reduce the resistance and reduce the heat at high sound velocity, but when there is an angle of attack, the flow field distribution on the upper and lower surfaces is asymmetric The greater the impact on the aircraft, the greater the pressure and temperature difference between the upper and lower walls. When the incoming flow is attached to the wall again, hot spots will form. A single commutator cone, when the aircraft is flying at a higher Mach number, the heating area of the commutator cone is small but the local heat flow is too large, often causing damage to the ablative structure. Therefore, in this paper, starting from the axisymmetric N-S equation, the flux splitting of the convection term adopts the AUSM+ format, and the reverse jet model and the rectifying cone model are numerically simulated. And a method of combined jet flow drag reduction and heat reduction is given to analyze the numerical simulation flow field. By analyzing the effects of different Mach numbers, different angles of attack, and different total pressure ratios on the flow field, valuable conclusions are drawn, which can provide some technical support for engineering design.

\section{Physical Model and Numerical Method}

2.1. Physical Model and Meshing. The jet test model [8-11] is shown in Figure 2. The radius of the front bluff body is $25 \mathrm{~mm}$, and the diameter of the symmetrical center nozzle is $4 \mathrm{~mm}$. In the test, nitrogen gas is jetted in reverse at a Mach number of 1 .

The numerical simulation experiment in this paper attempts to use more common air as the jet medium. Assume that the jet gas satisfies the complete gas state equation, i.e.,

$$
p=\rho_{i} R T=\rho_{i} \frac{R_{m}}{M_{i}} T .
$$

In the formula is the universal gas constant, the density of a gas, and the molar mass of a gas. According to equation (1), under isentropic conditions, the total pressures of nitrogen and air are, respectively,

$$
\begin{gathered}
P_{j 0 N_{2}}=\rho_{N_{2}} \frac{R_{M}}{M_{N_{2}}} T_{j 0 N_{2}}, \\
P_{j 0 \text { Air }}=\rho_{\text {Air }} \frac{R_{M}}{M_{\text {Air }}} T_{j 0 \text { Air }} .
\end{gathered}
$$

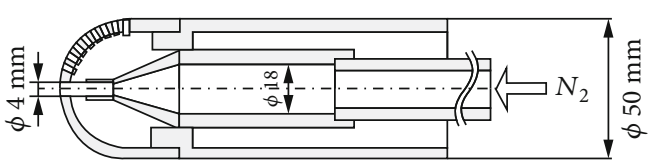

Figure 2: Experimental model.

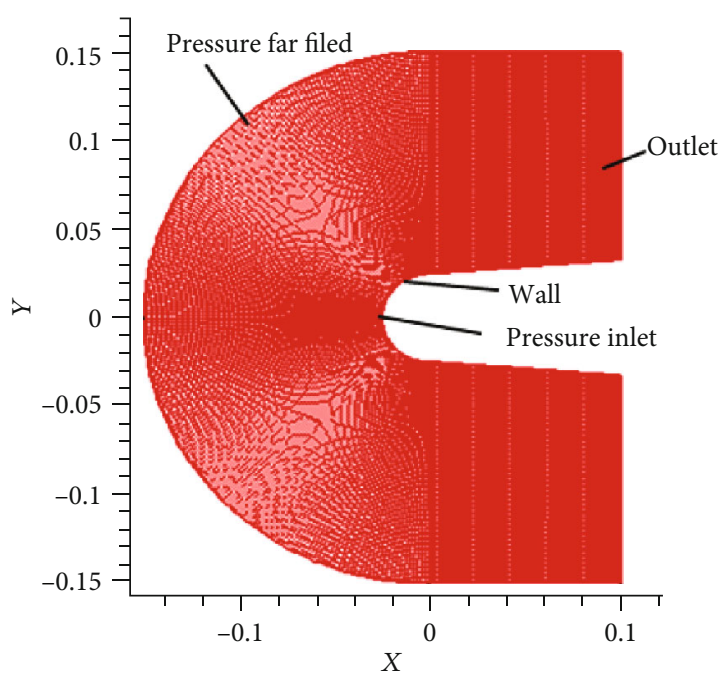

FIGURE 3: Numerical simulation grid.

In the formula, $\mathrm{Pj} 0$ and $\mathrm{Tj} 0$ represent the total pressure and temperature of the jet gas, respectively. Assuming that the density of nitrogen and air is equal to the total temperature, according to equations (2) and (3), the total pressure relationship between nitrogen and air under isentropic conditions is

$$
P_{j 0 \text { Air }}=\frac{M_{N_{2}}}{M_{\mathrm{Air}}} P_{j 0 N_{2}}=\frac{28}{28.9} P_{j 0 N_{2}} .
$$

Therefore, when air is selected as the jet medium, in order to match with the test, the total pressure of the jet can be processed according to equation (4).

In this paper, the axisymmetric N-S equation is used as the governing equation, the radius of the ball head of the aircraft is $25 \mathrm{~mm}$, the radius of the nozzle is $2 \mathrm{~mm}$, the axial length is $125 \mathrm{~mm}$, the numerical simulation model is a two-dimensional structured grid, and the grid model performs boundary layer encryption near the wall surface. The number of grids along the wall direction from one end of the nozzle is 240 , and the number of grids in the other direction is 200 . The grid model is shown in Figure 3.

2.2. Governing Equations and Boundary Conditions. Use FLUENT to obtain calculated data, the calculated control equation adopts the axisymmetric N-S equation with chemical reaction [30-32]. Since the flow parameters are 
TABLE 1: Boundary conditions.

\begin{tabular}{|c|c|c|c|c|}
\hline Free flow & $\begin{array}{c}\text { Mach number } \\
3.98 \\
\end{array}$ & $\begin{array}{c}\text { Angle of attack } \\
0,5,10 \\
\end{array}$ & $\begin{array}{c}\text { Total pressure } \\
1.37 \mathrm{MPa} \\
\end{array}$ & $\begin{array}{c}\text { Total temperature } \\
397 \mathrm{~K} \\
\end{array}$ \\
\hline \multirow{2}{*}{ Reverse jet } & Mach number & \multicolumn{2}{|c|}{ Total pressure ratio } & Total temperature \\
\hline & 1.0 & \multicolumn{2}{|c|}{$0,0.4,0.6$} & $300 \mathrm{~K}$ \\
\hline \multirow{2}{*}{ Wall surface } & \multicolumn{4}{|c|}{ Total temperature } \\
\hline & \multicolumn{4}{|c|}{$295 \mathrm{~K}$} \\
\hline
\end{tabular}

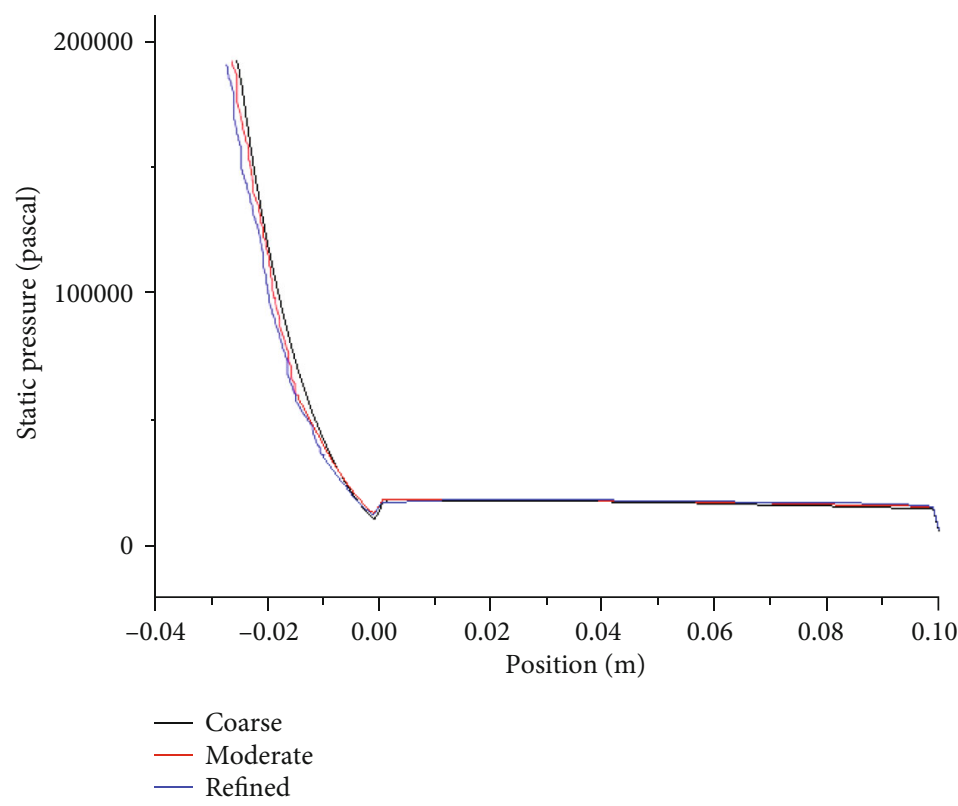

(a) Comparison of wall pressure of different grids

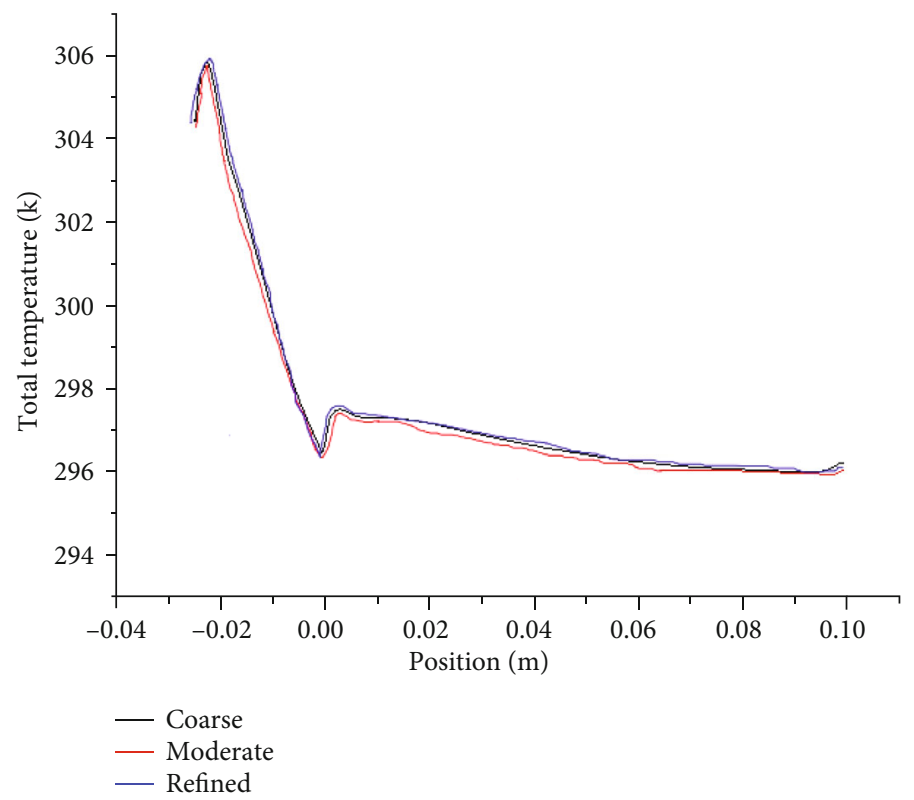

(b) Comparison of wall temperature of different grids

FIgURE 4: Comparison of different scale grids. 


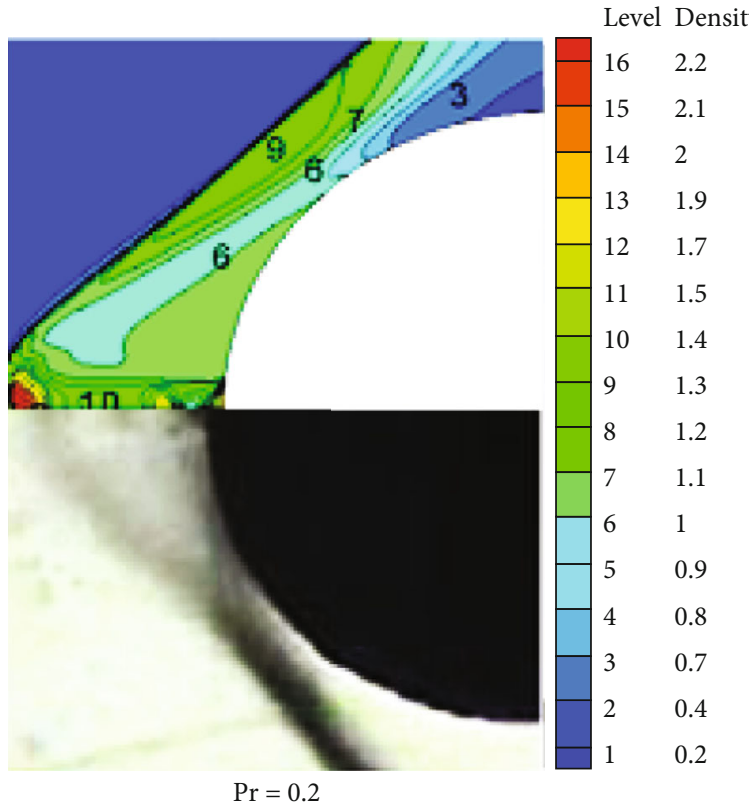

(a) $\operatorname{Pr}=0.2$

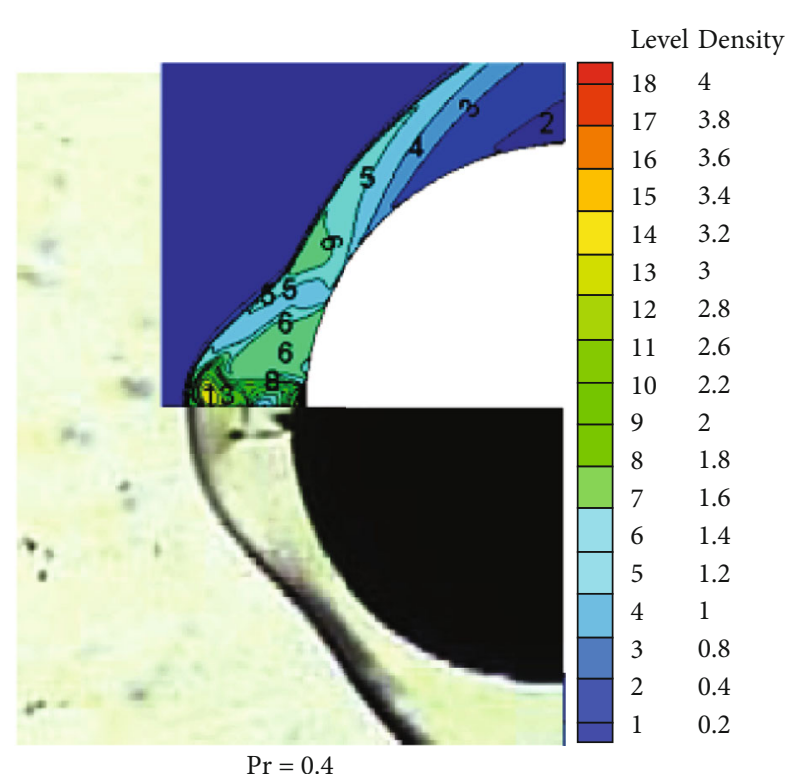

(b) $\operatorname{Pr}=0.4$

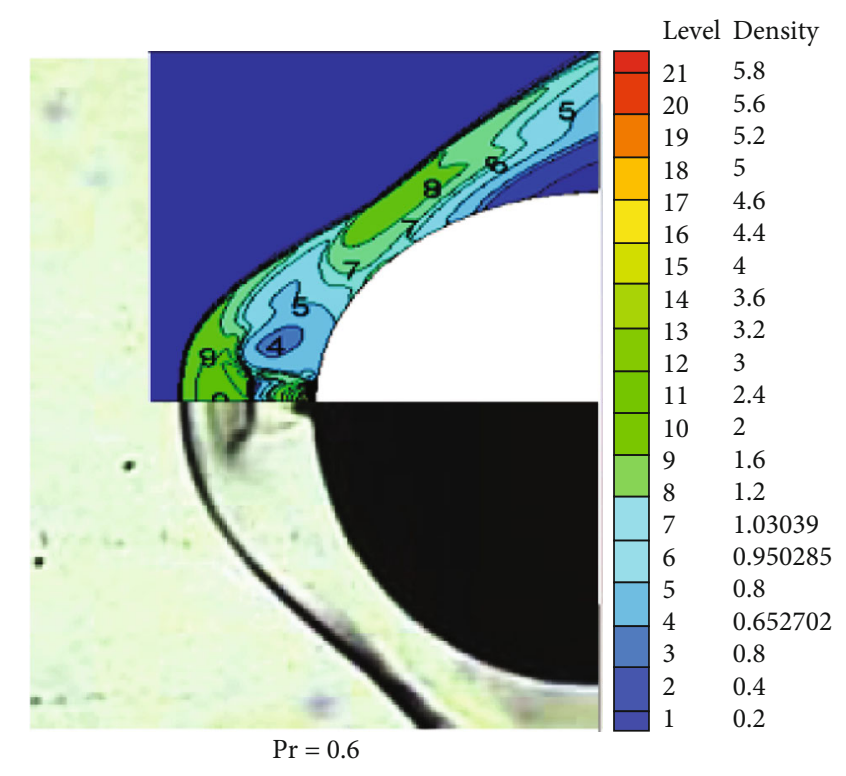

(c) $\operatorname{Pr}=0.6$

FIGURE 5: Comparison of simulation and experimental results.

used as reference quantities, the relevant parameters in the equation are dimensionless, where time $t$ is dimensionless with $L_{\infty} / V_{\infty}$, where the pressure $P$ is dimensionless with $\rho_{\infty}$ $V_{\infty}^{2}$. The total energy $E$ and total enthalpy $H_{0}$ are dimensionless with $V_{\infty}^{2}$. The control equation after calculating the dimensionless in the coordinate system $(\xi, \eta, \tau)$ is.

$$
\frac{\partial \vec{Q}}{\partial \tau}+\frac{\partial \vec{F}}{\partial \xi}+\frac{\partial \vec{G}}{\partial \eta}+\vec{H}=\frac{1}{R e}\left(\frac{\partial \vec{F}_{V}}{\partial \xi}+\frac{\partial \vec{G}_{V}}{\partial \eta}+\vec{H}_{V}\right)+\vec{W}
$$

where $\vec{Q}=\boldsymbol{J}\left[\rho_{i} \rho \rho u \rho v \rho E\right]^{\mathrm{T}}$ is a conserved variable; $\vec{F}$ and $\vec{G}$ are the nonstick flux; $\vec{F}_{V}$ and $\vec{G}_{V}$ are the Viscous flux.

The governing equation is solved by a density-based solution method. The splitting format of the convection term uses the AUSM+ format, the diffusion term uses the central difference format, and the finite volume method is used to solve the flow field. The turbulence model of reverse jet simulation uses the SST $k-\omega$ turbulence model [33], which has a similar form to the standard $k-\omega$ model. The SST $k-\omega$ turbulence model combines the advantages 


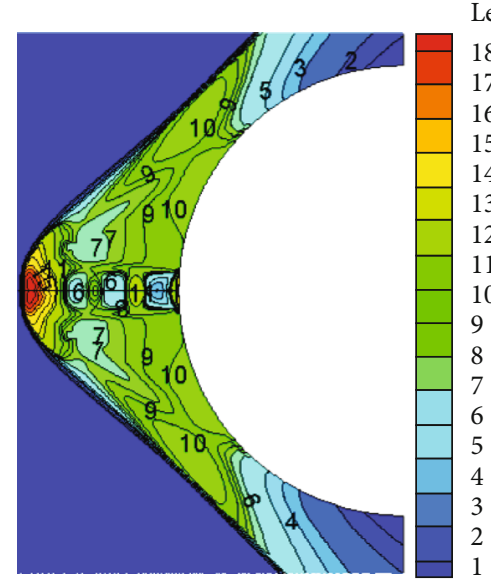

(a) Long jet mode
Level Pressure

190000
180000
170000
160000
140000
120000
110000
90000
84893.8
83478.2
82596.6
81726.2
80000
70000
60000
50000
30000
20000

20000

Figure 6: Cloud diagram of pressure distribution under two modal flows.

of both $k-\omega$ and $k-\varepsilon$. It has better performance in the wall boundary layer, free shear flow, and low Reynolds number flow, and has obvious advantages in capturing the flow, separation, and transition of the boundary layer [34-37].

$$
\begin{gathered}
\frac{\partial}{\partial t}(\rho k)+\frac{\partial}{\partial x_{i}}\left(\rho k u_{i}\right)=\frac{\partial}{\partial x_{j}}\left(\Gamma_{k} \frac{\partial k}{\partial x_{j}}\right)+\tilde{G}_{k}-Y_{k}+S_{k} m, \quad(6) \\
\frac{\partial}{\partial t}(\rho \omega)+\frac{\partial}{\partial x_{i}}\left(\rho \omega u_{i}\right)=\frac{\partial}{\partial x_{j}}\left(\Gamma_{\omega} \frac{\partial \omega}{\partial x_{j}}\right)+G_{\omega}-Y_{\omega}+D_{\omega}+S_{\omega} .
\end{gathered}
$$

In formulas (6) and (7), $\tilde{G}_{k}$ represents the amount of turbulent kinetic energy generated, and $G_{\omega}$ represents the amount of generated dissipation rate, both of which are caused by the average velocity; $\Gamma_{k}$ and $\Gamma_{\omega}$ represent the effective diffusion coefficients of and, respectively; $Y_{k}$ and $Y_{\omega}$ represent the dissipation of and caused by turbulence, respectively; $S_{k}$ and $S_{\omega}$ are custom source terms.

The fluid of the jet and the medium of the external static flow field are ideal gases. The boundary conditions are the pressure far field and the pressure outlet, the injection port is the pressure inlet, and the wall surface is a nonslip wall surface. The total pressure ratio $\mathrm{Pr}$ is simulated and calculated; as for the flow field at $0.2 \sim 0.6$ [14], the selected working conditions are shown in Table 1.

\section{Calculation Results and Analysis}

3.1. Confirmatory Calculation. The grid in this paper is a twodimensional structural grid. As shown in Figure 3, the grid model is encrypted by the boundary layer near the wall. Taking into account the influence of the number of grids on the calculation results, three different grids are used to verify the grid independence of the reverse jet flow, which are coarse grid $(180 \times 160,160$ along one end of the nozzle, the other direction is 180$)$, moderate grid $(240 \times 200)$, and refined grid $(350 \times 260)$. Calculate the incoming flow Mach number 3.98, the jet pressure ratio is 0 , and the wall static pressure and temperature distribution in the case of different types of grids. As shown below.

By comparing Figure 4, we can know that the predicted wall static pressure and temperature of the three different grids show good consistency, and the error range of the different grids is not large, which is within an acceptable range. Combined with the calculation time, we choose the moderate grid for this calculation.

After the independence of the grid, in order to verify the credibility of the numerical simulation model and various numerical setting conditions in this article, this section firstly refers to the experimental model provided in the literature [8-11] for numerical modeling, and according to the experimental conditions, set the working conditions of numerical simulation. Figure 5 shows the structure of the jet interference flow field at the front end of the bluff body when the incoming Mach number is 3.98 and the total pressure ratio is $0.2,0.4$, and 0.6. Observing Figures 5(a)-5(c), it can be seen that the numerical simulation results are consistent with the experimental schlieren diagrams in form, and the motion characteristics of the flow field behind the waves are in good agreement with the experimental results.

The basic structure of the jet interference flow field includes primary shock wave, secondary shock wave, shock wave intersection area, stagnant disk, shock wave, and flow area in front of the stagnant disk, jet recirculation area after stagnant disk, and attached area. The stagnant disk and its attached fluid layer completely isolate the future flow from the wall, similar to a fairing made of low-temperature flowing gas at the front end of the bluff body, which blocks the direct contact between the wall and the incoming flow. This shows that the physical model, grid design, and numerical simulation methods used in this paper are reasonable and the calculation results are relatively accurate. 


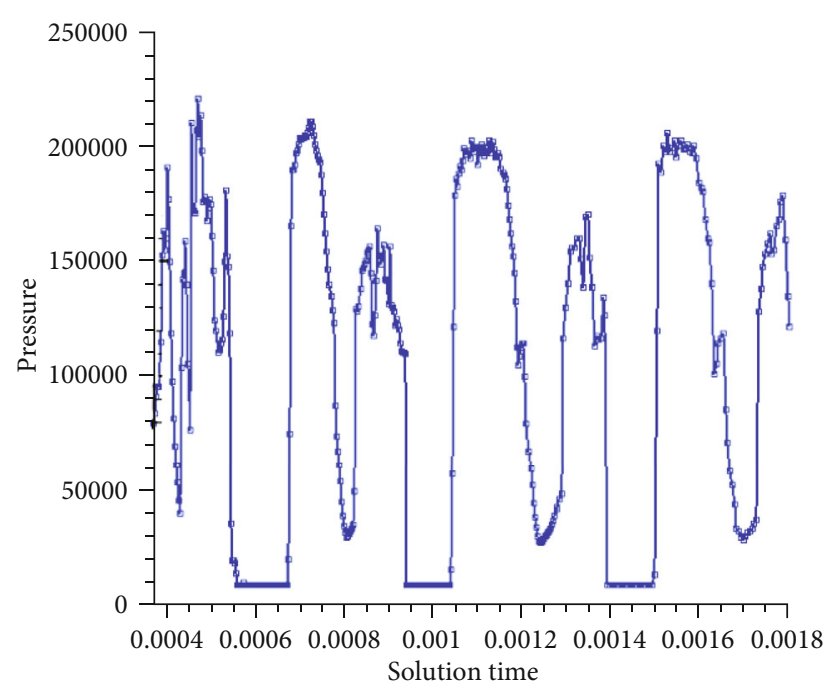

(a) Total pressure ratio 0.2

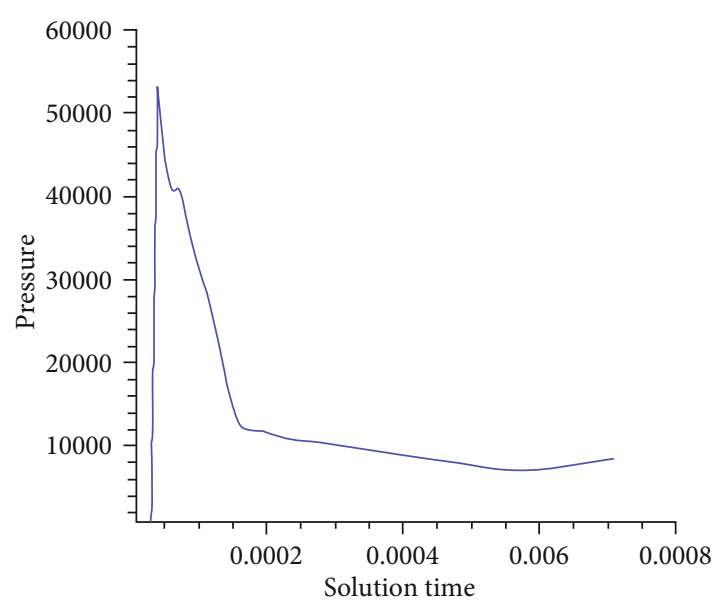

(b) Total pressure ratio 0.4

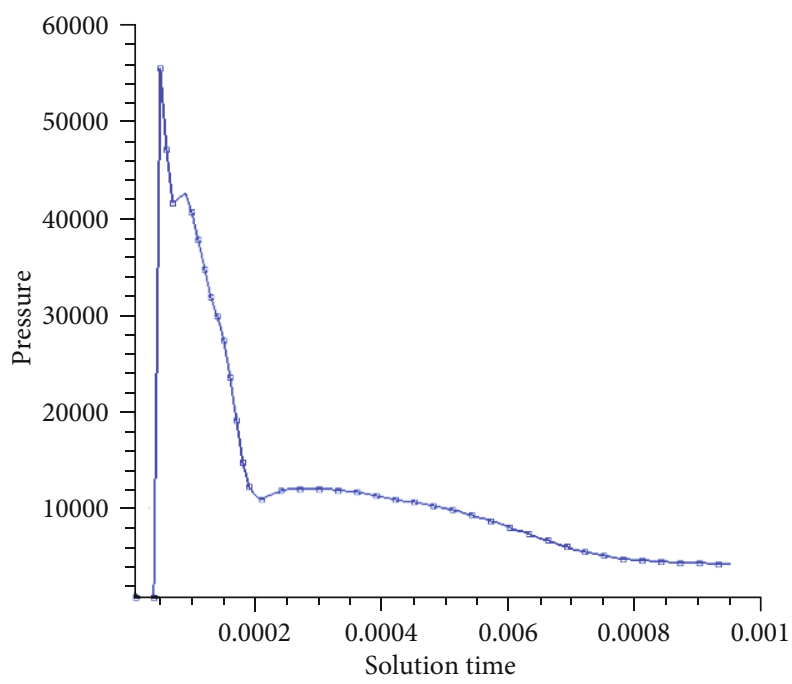

(c) Total pressure ratio 0.6

Figure 7: Pressure changes with time at a position behind the stagnation disk.

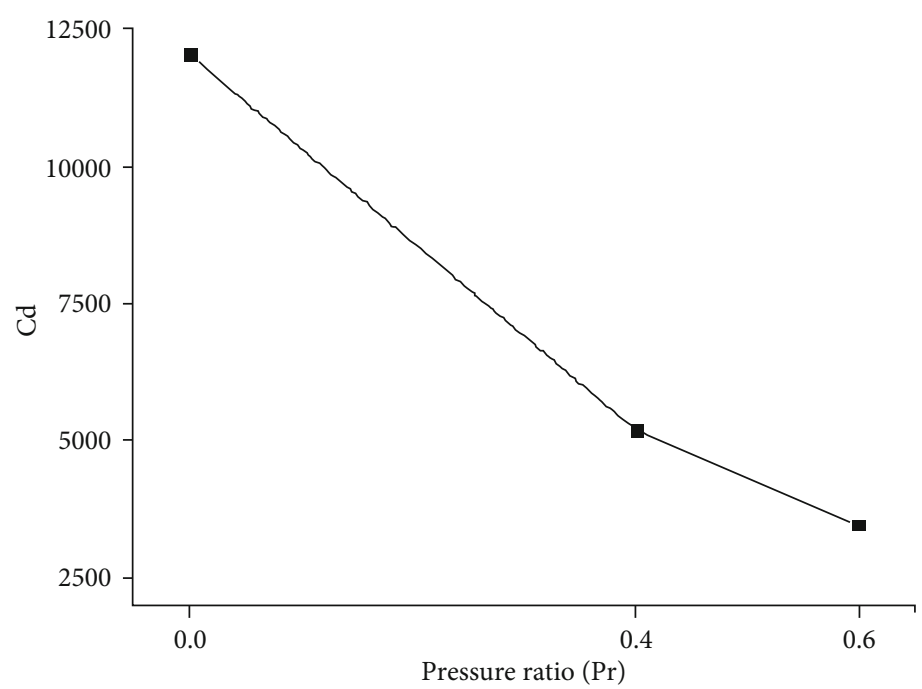

FIGURE 8: Resistance coefficient changes with pressure ratio at different pressure ratios without the angle of attack. 


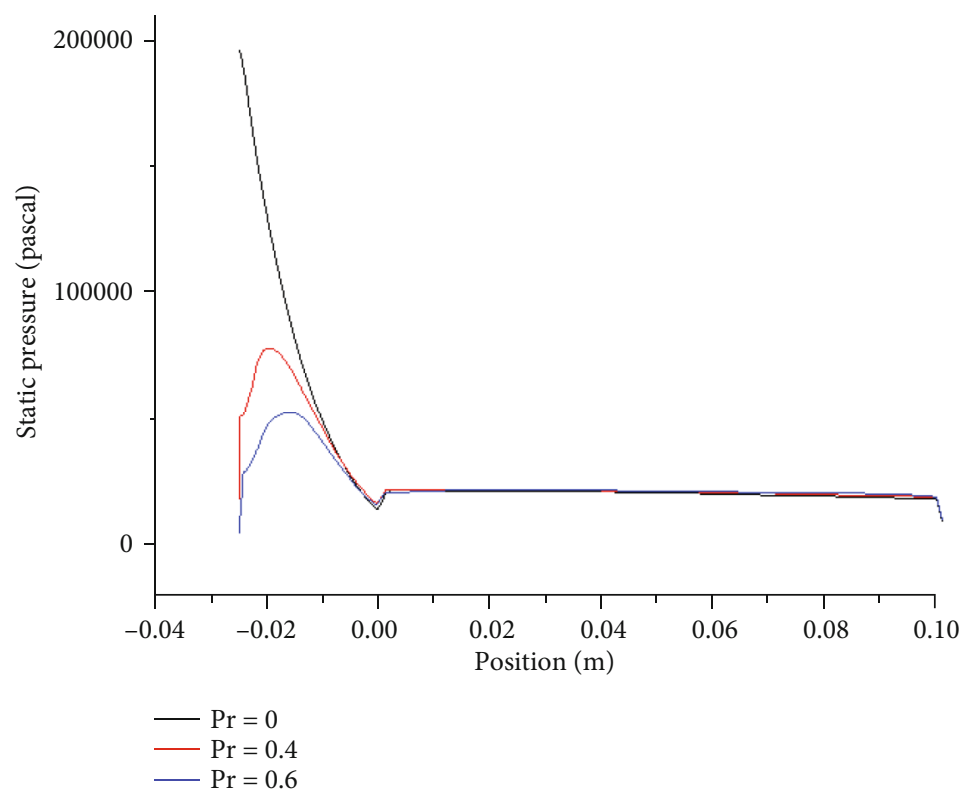

(a) Pressure distribution on the upper and lower walls

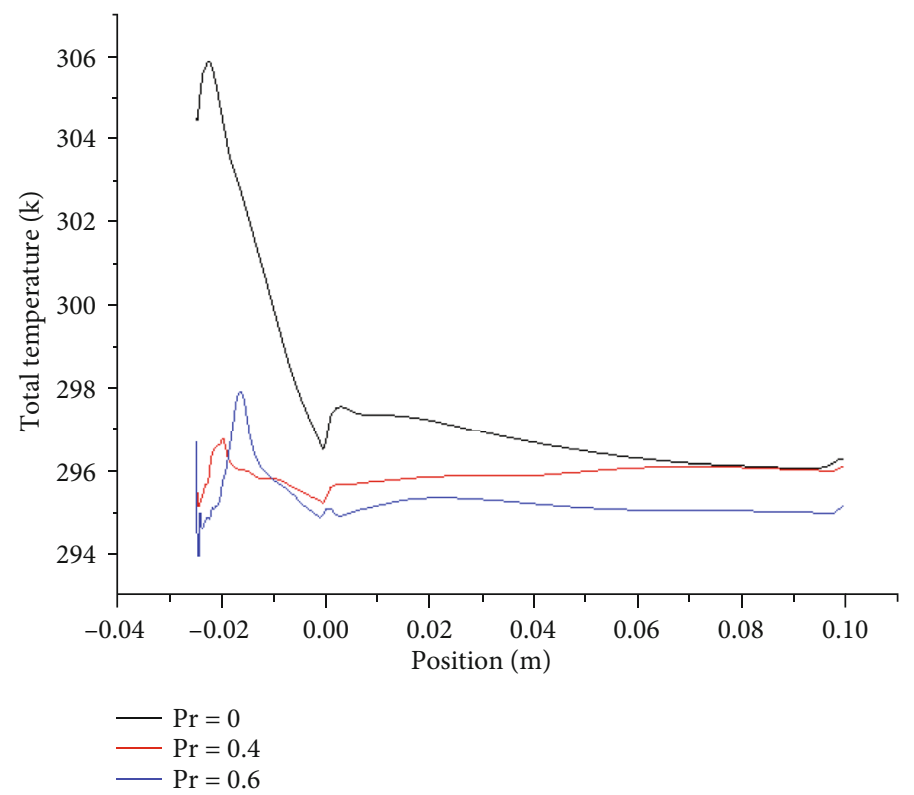

(b) Temperature distribution of upper and lower walls

Figure 9: Pressure and temperature distribution on the wall surface of the ball head.

3.2. Two Modes of Jet Flow Field. There are two flow modes in the reverse jet flow field, namely, long jet mode and short jet mode. The effect of the front return area causes the head pressure to drop, and the pressure resistance of the blunt body decreases. When the jet pressure ratio to the total pressure ratio $\operatorname{Pr}$ is less than a certain critical value in the process of reverse jet flow, a long jet mode appears in the flow field, and the main shock wave in the head forms an elliptical protrusion, which is equivalent to extending a rod in front. The object is shown in Figure 6 . When the total pressure ratio is greater than this critical value, the flow field is short jet mode, and only one stable jet element appears stagnation disk at the end of the jet, and the stagnation disk and the shear layer on the side of the jet form a stable recirculation zone.

A certain point behind the stagnation disk after the flow field is stable is selected as the research object, and the transient change of the pressure parameter with time at this point when the total pressure ratio is $0.2,0.4$, and 0.6 is extracted, as shown in Figure 7. Observing Figure 7(a), we can see from the curve in the figure that the parameters in the interference flow field have obvious periodic changes. The change period under the condition of solving parameters in this paper is about 0.0004 seconds. For each period, there are certain fluctuations in the values of the points on the parameter curve, but the overall change trend is consistent, and the waveform function 


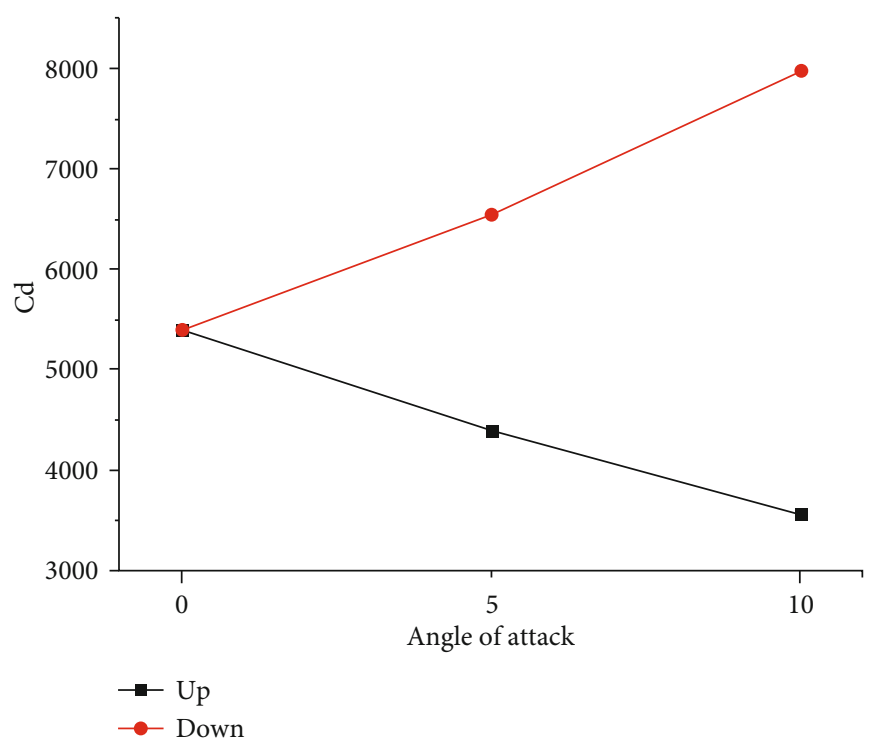

(a) $\operatorname{Pr}=0$

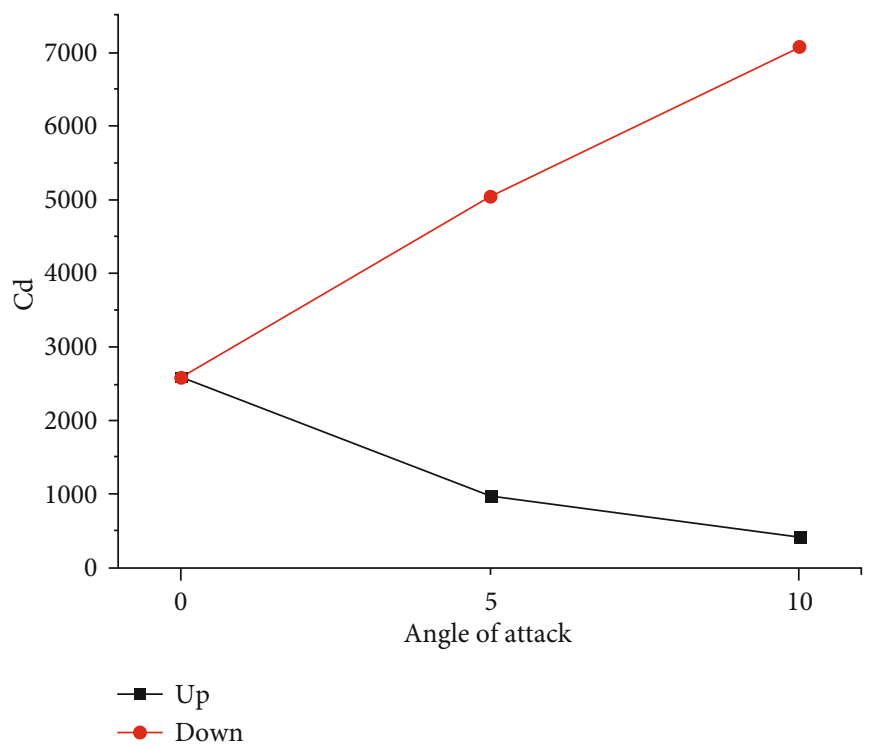

(b) $\operatorname{Pr}=0.4$

Figure 10: Continued. 


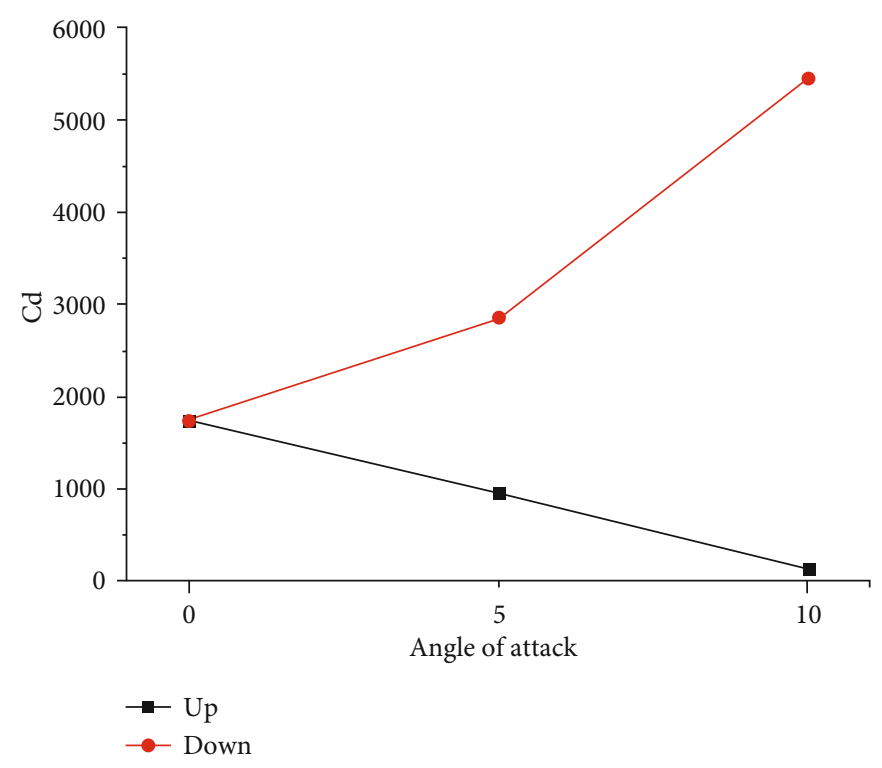

(c) $\operatorname{Pr}=0.6$

FigURE 10: Resistance coefficients of upper and lower walls at different pressure ratios and angles of attack.

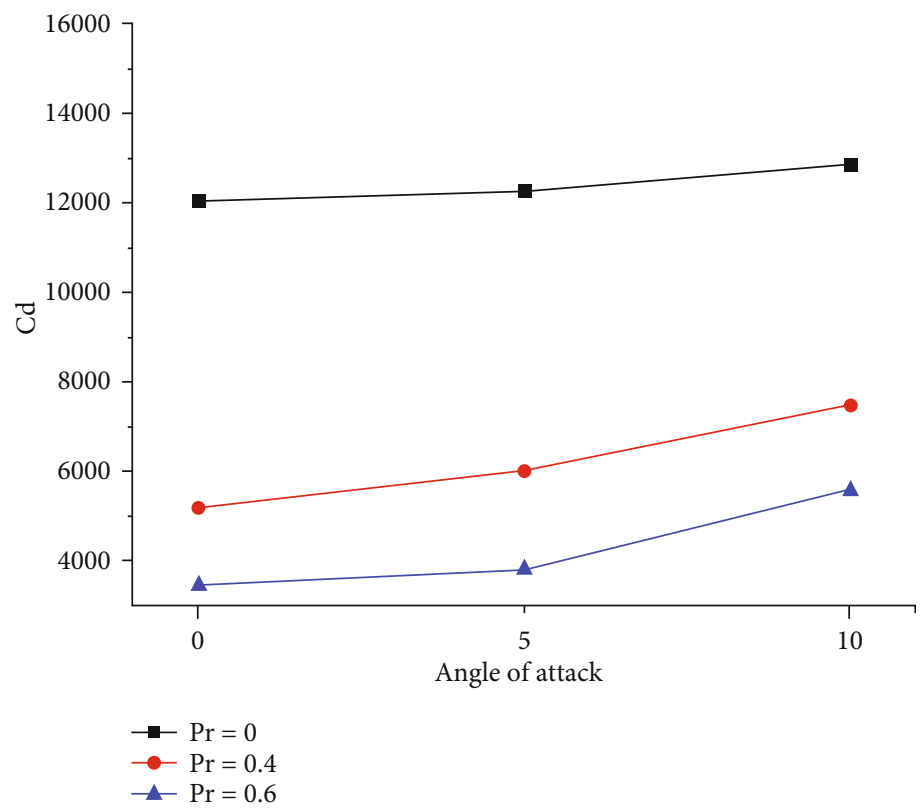

FIGURE 11: Resistance coefficient changes with the angle of attack at different pressure ratios.

is similar to the triangular function wave. When the total pressure ratio increases, the parameters fluctuate and change at this point in the initial stage of the calculation, and then the parameter value rapidly decreases, and the gentle change gradually stabilizes. From this preliminary judgment, in the initial stage of the jet flow, because the flow field is unstable, the parameters of each point of the entire disturbance flow field are also fluctuating. With the change of time, the disturbance flow field tends to be stable, and various parameters start to fluctuate slightly around a certain constant value. The change is not obvious. At this time, the macroscopically observed jet flow and the mainstream disturbance flow field are relatively stable. In the reverse jet flow, the flow field structure of the short jet mode is relatively stable. In the subsequent study, the selection of the total pressure ratio $R_{P}$ is the pressure ratio at which the short jet mode appears.

\subsection{Numerical Simulation Analysis of Single Reverse Jet}

(1) Analysis of drag reduction and heat reduction without angle of attack.

A low-pressure recirculation zone appears on the outside of the reverse jet stream, which reduces the pressure on the windward side and reduces the aerodynamic resistance of the aircraft. Obtained from the numerical simulation results, 


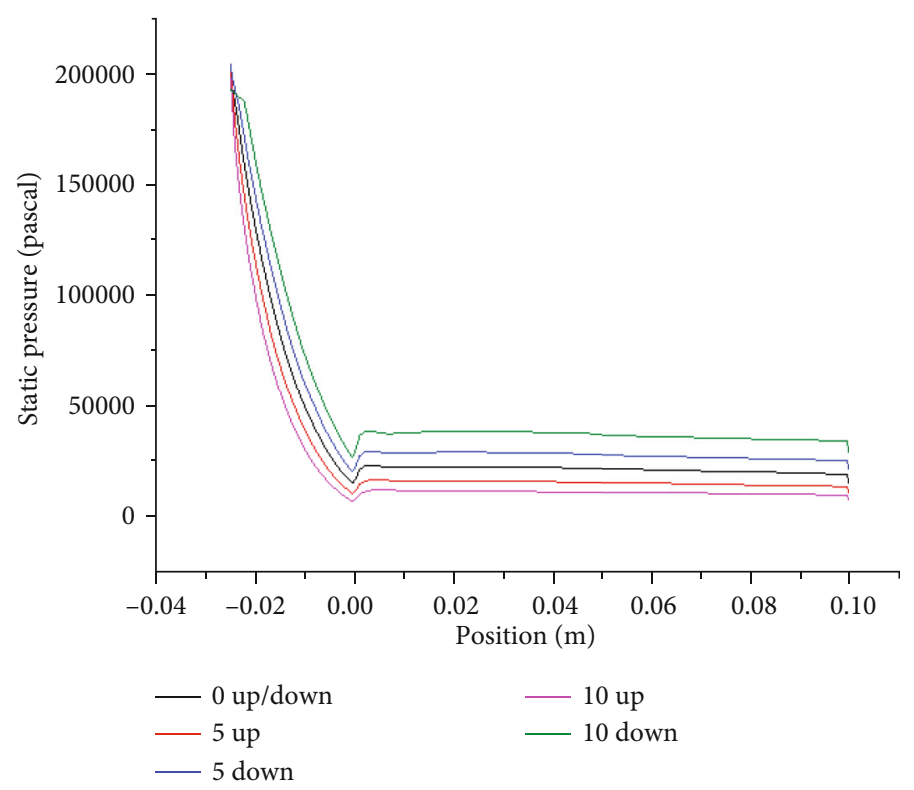

(a) Pressure distribution on the upper and lower walls

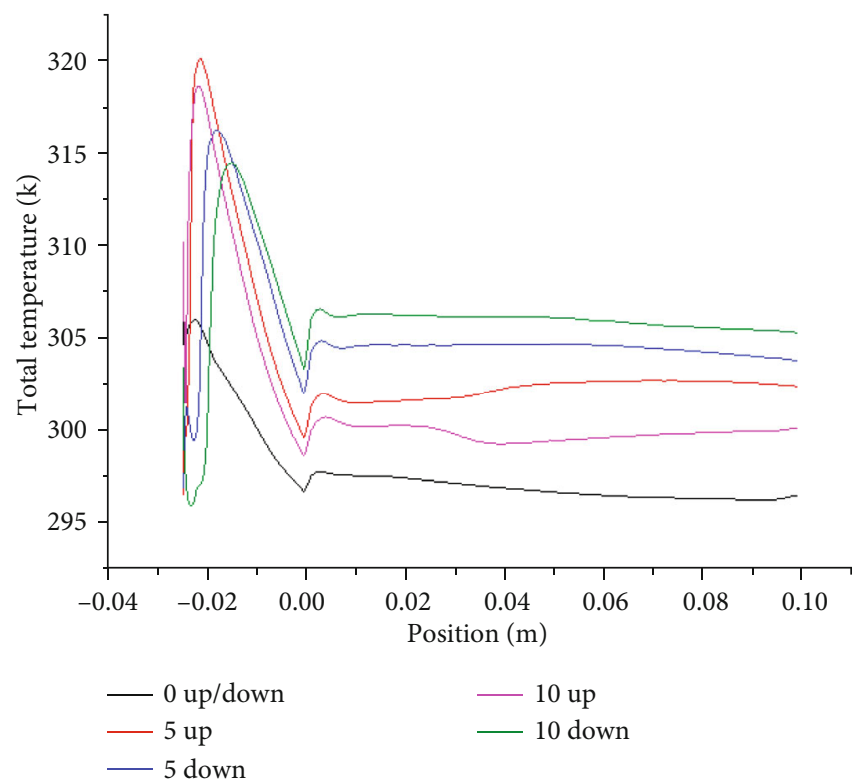

(b) Temperature distribution of upper and lower walls

FiguRE 12: The pressure and temperature distribution of the upper and lower walls of $\operatorname{Pr}=0$ at different angles of attack.

observing Figure 8, we can see that with the increase of the pressure ratio when there is no angle of attack, the drag reduction effect of the reverse jet flow is more obvious; The drag reduction effect is the best when the pressure ratio is 0.4 , and the drag reduction effect is not obvious when the pressure ratio is 0.6 when the specific pressure ratio is 0.4 , but the resistance coefficient at this time is much lower than the state without jet flow. In the case of no angle of attack, the reverse jet flow has a drag reduction effect of up to $70.4 \%$ compared with no jet flow.

The free flow generates a strong shock wave at the head of the aircraft, and the pressure, density, and temperature increase sharply. Due to the addition of the jet, the original flow field structure becomes more complicated. Figure 9 shows the pressure and temperature distribution on the upper and lower walls. Because the jet pushes the shock wave originally generated in the head of the aircraft away from the wall of the aircraft head, the Mach disk is formed in front of the jet, and a low-pressure recirculation zone is formed behind the Mach disk. The outer edge of the recirculation zone is the shear layer of the jet and the incoming stream. The incoming stream bypasses the head compression shock wave and flows downstream along the shear layer, so that the shear layer is attached to the surface of the aircraft head again, and the shear layer is cut off. The incoming flow is in direct contact with the wall surface, and this recirculation zone plays a major role in reducing the temperature of the aircraft head wall surface; With the increase of the pressure ratio, the bow-shaped shock wave of the head is pushed 


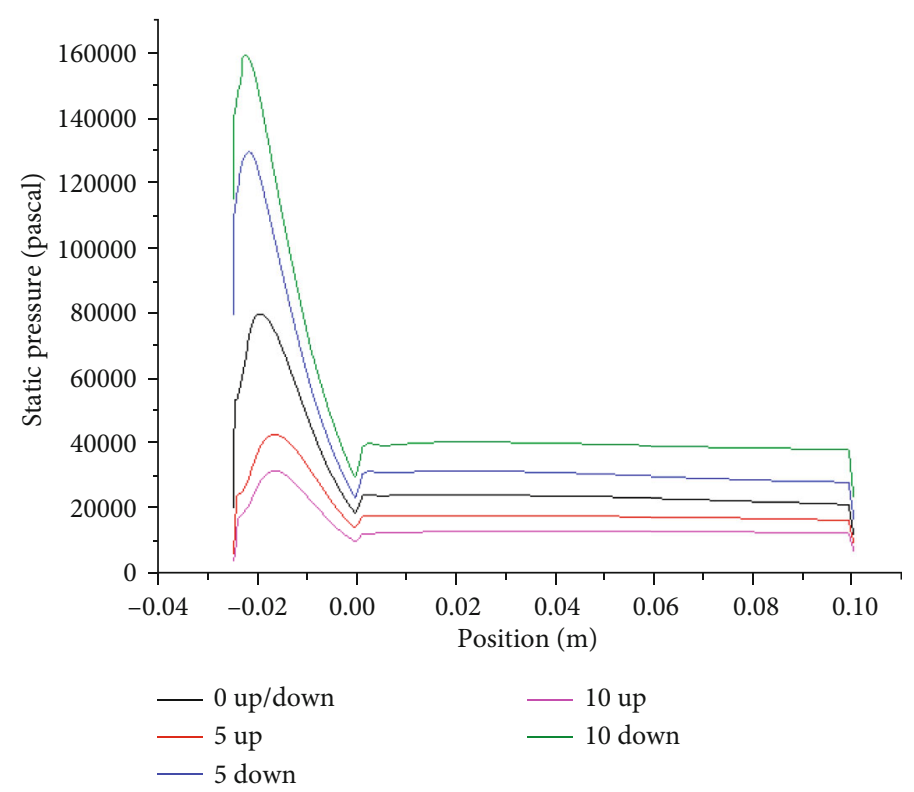

(a) Pressure distribution on the upper and lower walls

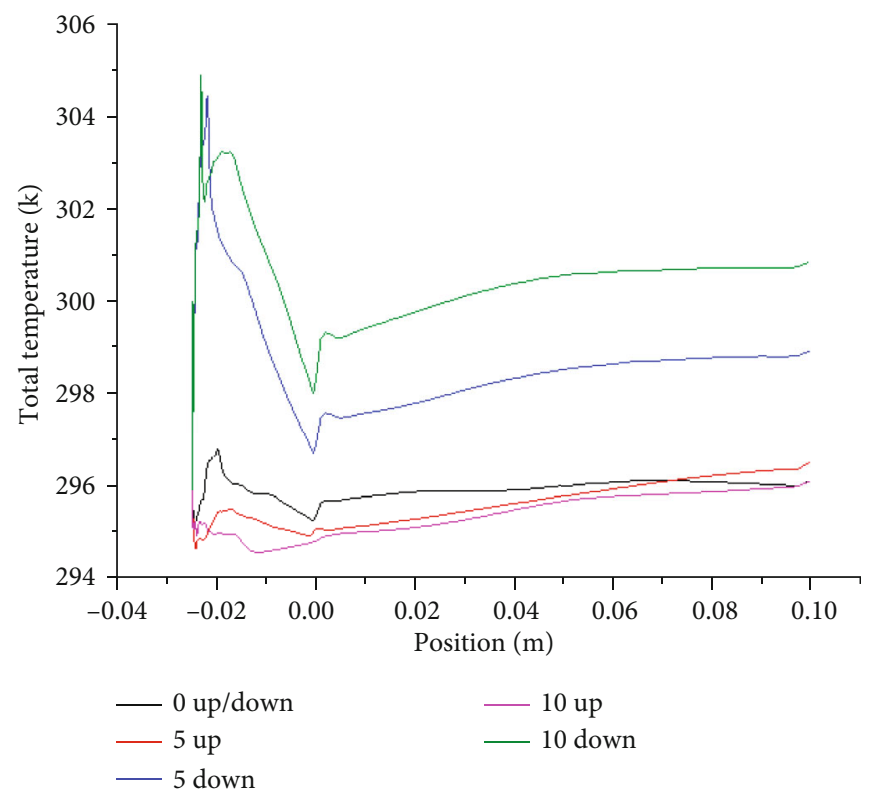

(b) Temperature distribution of upper and lower walls

FIGURE 13: The pressure and temperature distribution of the upper and lower walls of $\operatorname{Pr}=0.4$ at different angles of attack.

farther away from the aircraft head, and the formed recirculation area is larger, which causes the reattached shock wave to the rear edge of the aircraft wall surface, and the intensity is reduced, which plays a role in the aircraft. Very good drag reduction and cooling effect.

(2) Analysis of drag reduction and heat reduction at different angles of attack.

It is known from Figures 10 and 11 that as the total pressure ratio increases, the drag coefficient of the aircraft decreases; As the angle of attack increases, the drag coefficient also increases.
When there is no jet flow, the drag coefficient increases less with the angle of attack; The drag coefficient with jet flow increases with increasing angle of attack, but the jet flow resistance coefficient is much smaller than that without jet flow, indicating that with jet flow, the greater the angle of attack, the greater the impact on the drag coefficient. When the angle of attack is 0,5 , and 10 degrees under the condition of reverse jet flow, the reverse jet flow has a good drag reduction effect, which verifies the feasibility of the reverse jet flow to reduce the drag of the aircraft. But as the angle of attack increases, the greater the asymmetry of the flow field, the free-flowing shear layer will be attached to the wall, forming a hot spot, and a single reverse jet cannot solve this problem. 


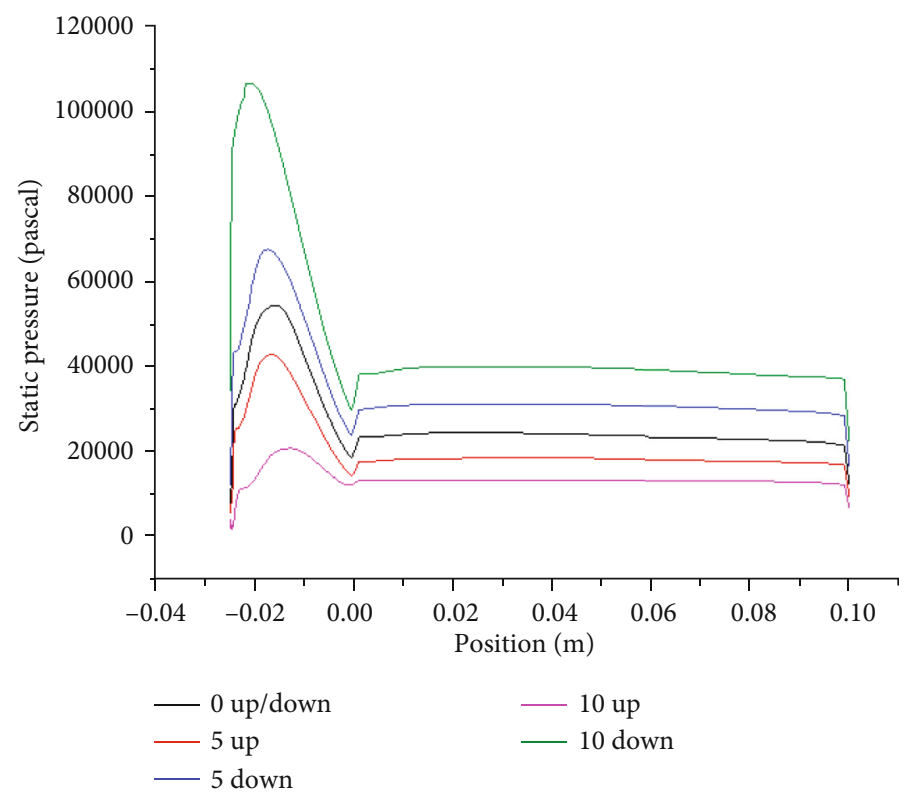

(a) Pressure distribution on the upper and lower walls

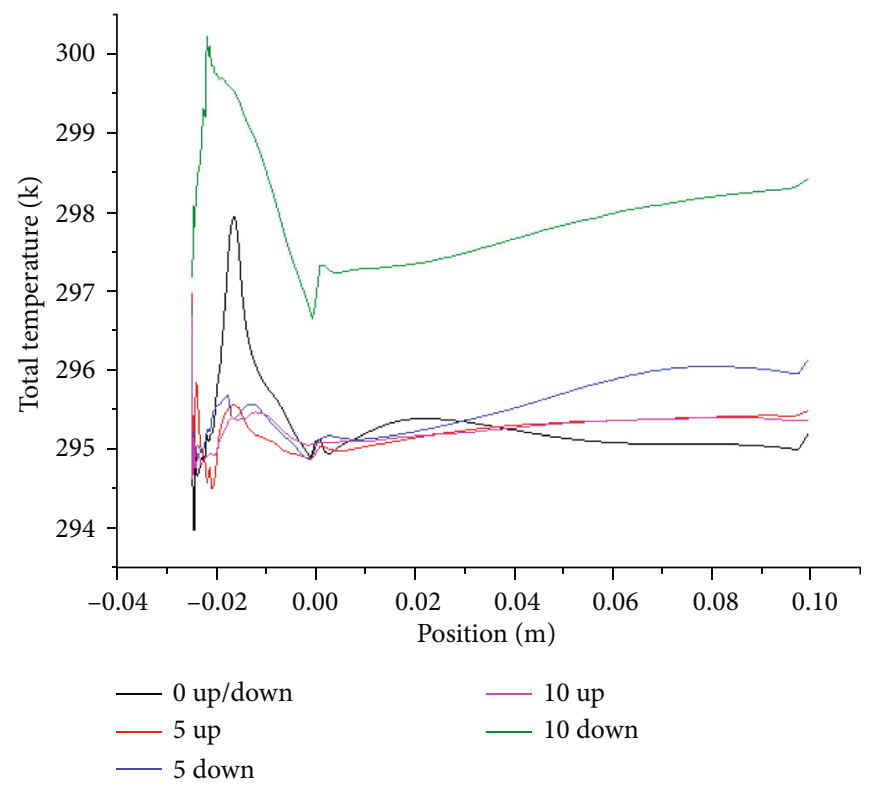

(b) Temperature distribution of upper and lower walls

FIGURE 14: The pressure and temperature distribution of the upper and lower walls of $\operatorname{Pr}=0.6$ at different angles of attack.

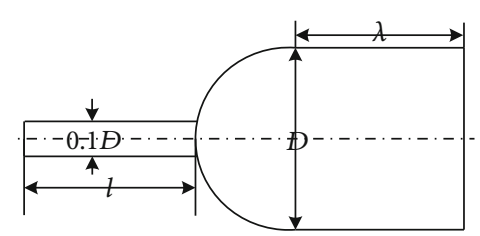

Figure 15: Rectifier cone configuration.

When the angle of attack of the aircraft changes, as shown in Figure 12-14, under the condition of constant pressure ratio, with the increase of the angle of attack, the head will reverse the compression formed by the jet and the incoming flow. The wave moves upward, the pressure and temperature of the lower wall surface are higher than the upper wall surface, and the drag coefficient is also higher than the upper wall surface. The pressure and temperature peaks of the upper wall surface are decreasing and move negatively in the axial direction against the incoming flow. The peak pressure and temperature of the lower wall surface are increasing and moving along the direction of the incoming flow along the positive direction of the lower wall surface, the upper and lower wall surfaces. The difference between the pressure and temperature increases with the angle of attack, indicating that the larger the angle of attack, the greater the impact on the aircraft. 


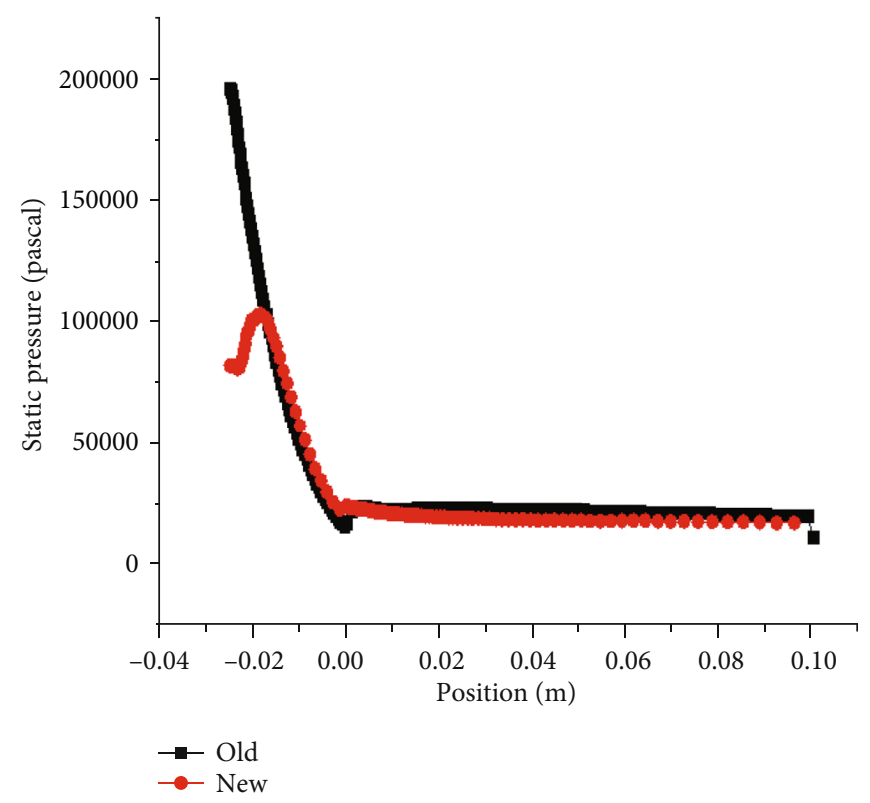

FIGURE 16: Comparison of pressure distribution between a single rectifier cone and a bluff body.
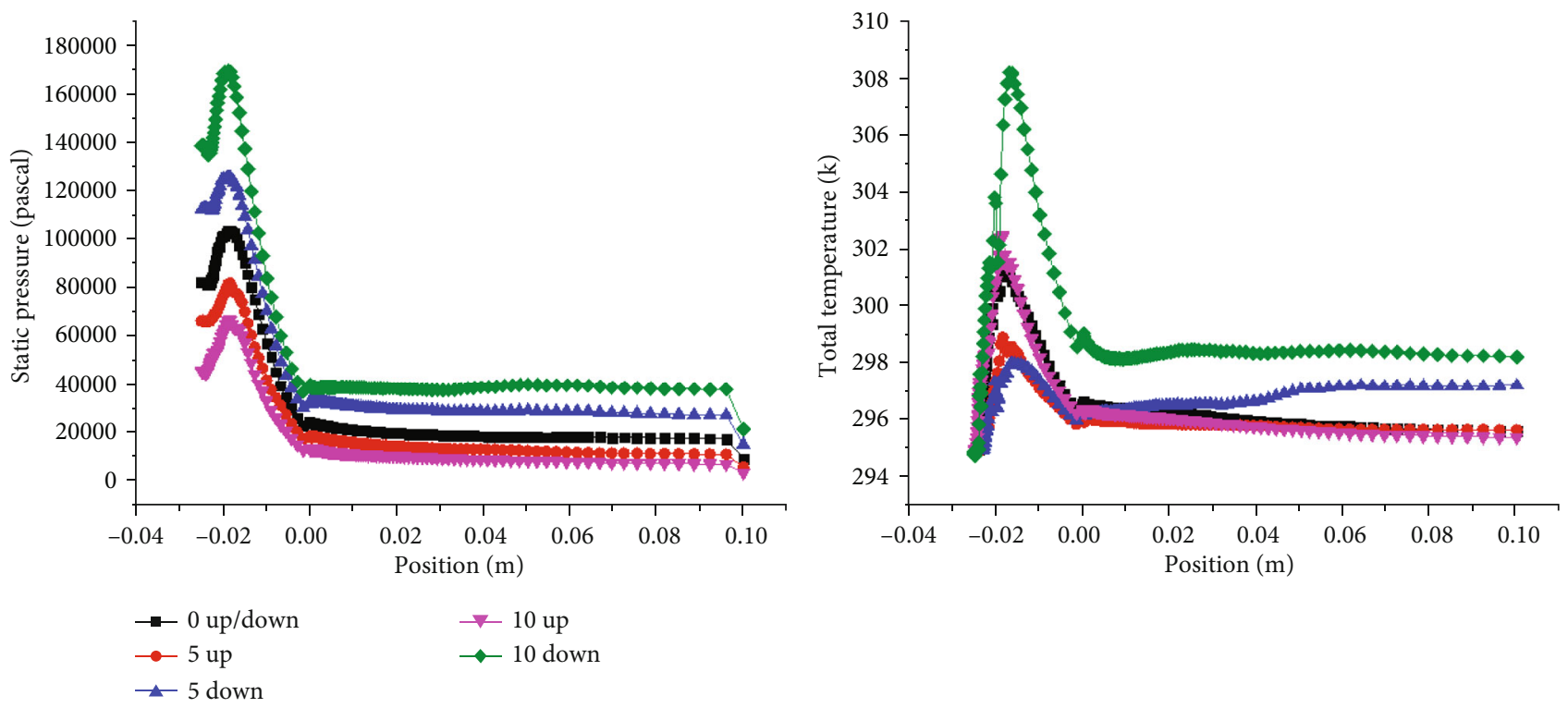

Figure 17: Pressure and temperature distribution of a single rectifier cone at different angles of attack.

3.4. Numerical Simulation Analysis of Single Rectifier Cone. The results in the previous section show that the jet can prevent the incoming flow from directly contacting the wall, effectively reducing the drag and reducing the pressure on the wall surface of the aircraft head. However, the flow field becomes complicated due to the effect of the jet, and the angle of attack has a significant impact on the aircraft. It poses a great threat to the safety of the aircraft. These are all due to the fact that the flow field structure formed by the jet cannot push the high-temperature shock farther, so that the shear layer is attached to the wall under the action of the incoming flow, forming a hot spot.

Therefore, the idea is to extend the nozzle against the direction of the incoming flow, so that the shock wave formed by the jet and the incoming flow will be farther away from the head of the aircraft, so that the shear layer will not reattach to the wall surface, so as to better reduce drag and heat. The configuration of the model is shown in Figure 15. In the case of no jet, the extended nozzle acts as a straightening cone. As shown in Figure 16, the effect of a single rectifier cone is compared with the wall pressure of a blunt body. As the angle of attack changes, Figure 17 shows the wall pressure and temperature distribution diagrams at different angles of attack. It can be seen that under the action of a single rectifier cone, the shoulder of the ball head is about 45 degrees, where the pressure peak and temperature peak are located, and the pressure and temperature gradually decrease along the ball head. The effect of the rectifier cone in the active protection of the aircraft in 


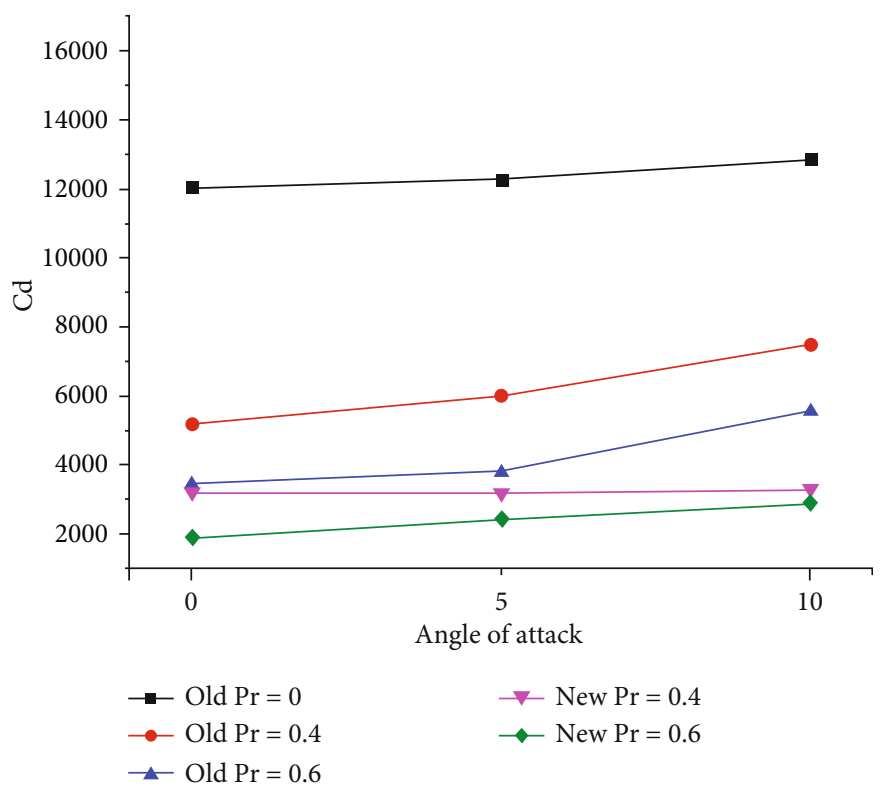

Figure 18: Resistance coefficient at different pressure ratios and angles of attack.

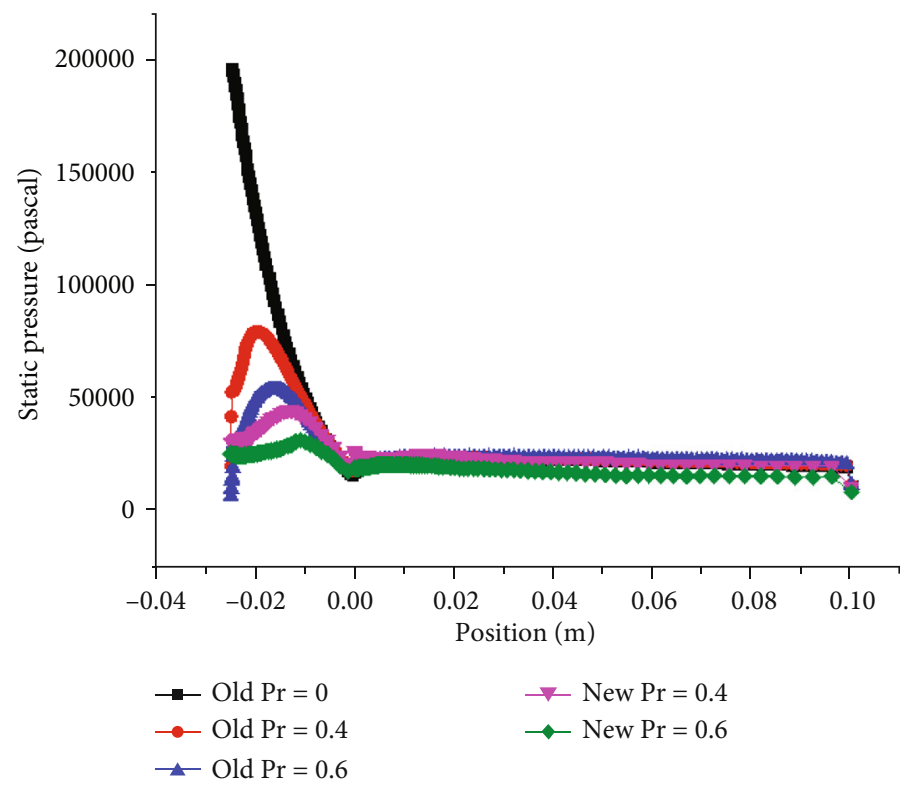

FIGURE 19: Wall pressure distribution diagram with different pressure ratios.

drag reduction and heat reduction is obvious. However, due to the high temperature, the rectifier cone is easy to ablate, and it is inconvenient to replace it frequently. So consider the way to combine the jet and the straightening cone.

\subsection{Numerical Simulation Analysis of the Combination of} Rectifying Cone and Jet. In order to solve the change of the angle of attack of the single reverse jet, the shear layer of the incoming flow will be attached to the wall, forming a hot spot, posing a threat to the safety of the aircraft. Single rectifier cone is easy to ablate and needs to be replaced frequently. So use a combination to overcome the problem.
When the new combination has an angle of attack, the complex wave system structure formed is no longer symmetrical. The greater the angle of attack, the greater the asymmetry, and the greater the difference between the upper and lower wall parameters, such as pressure, density, and temperature, the greater the drag coefficient of the aircraft; A bowshaped strong compression shock wave is formed in front of the nozzle with the incoming flow. Since the shock wave formed by the fluid ejected by the extended nozzle and the incoming flow is far away from the wall of the ball head body, the downward flow direction of the shock wave fails to form a reattachment shock wave with the wall surface, which reduces the wall pressure and temperature. Figure 18 

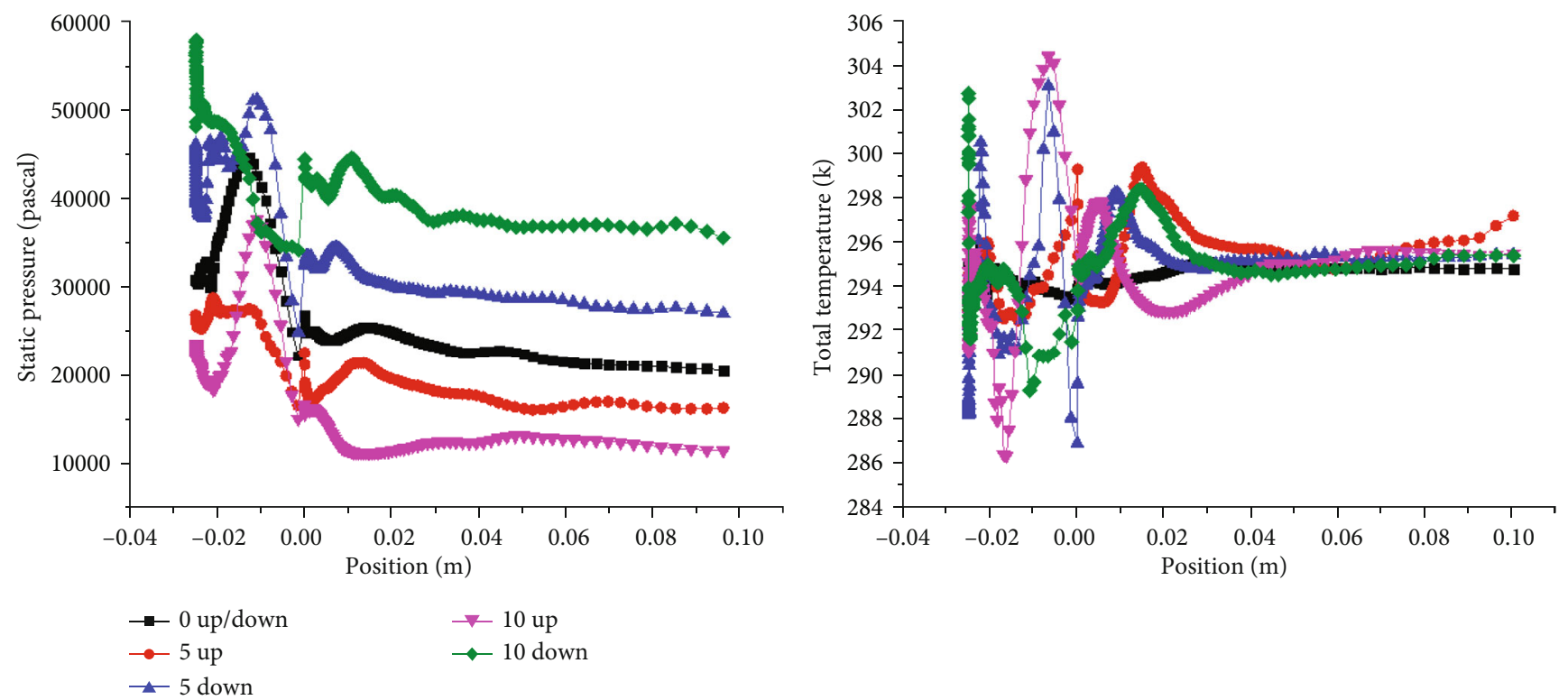

Figure 20: $\operatorname{Pr}=0.4$ wall pressure and temperature distribution at different angles of attack.
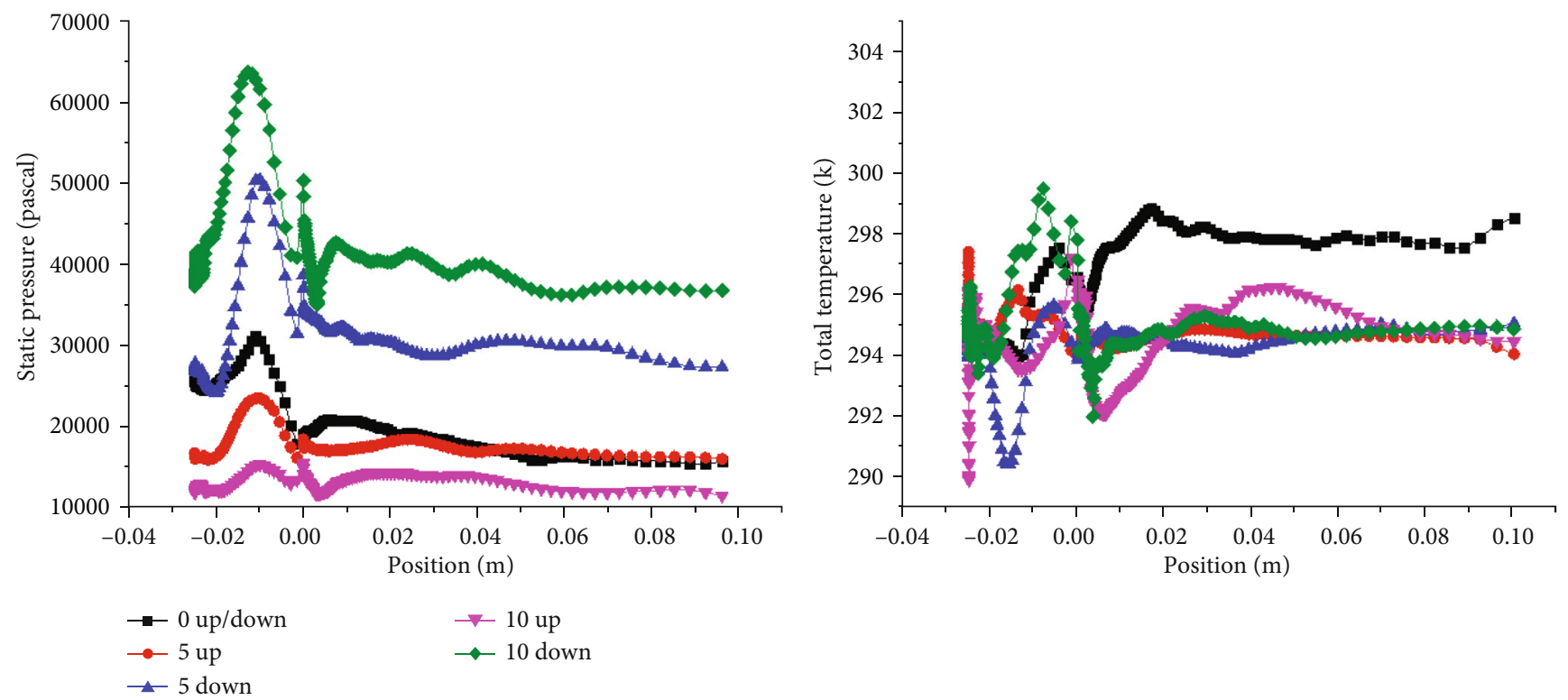

Figure 21: $\operatorname{Pr}=0.6$ wall pressure and temperature distribution at different angles of attack.

corresponds to the effect of the combined jet mode under different pressure ratios on the drag coefficient of the ballheaded aircraft. The reduction of the differential pressure resistance greatly reduces the drag. Figure 19 corresponds to the influence of the combined jet mode under different pressure ratios on the wall pressure distribution of the spherical nose body aircraft. It can be seen that the peak static pressure of the wall surface drops significantly under the action of the new combined jet.

The changes in wall pressure and temperature of the new combined jet at different pressure ratios with the angle of attack are shown in Figures 20 and 21. It can be obtained that as the angle of attack increases, the position of the attached shock wave moves forward, and the pressure and temperature of the upper and lower walls differ greatly.

It can be obtained by observing the clouds at different angles of attack shown in Figure 22. The ratio of the compressed shock wave formed by the jet and the incoming flow is "protective umbrella," and the positive shock wave is the "umbrella tip." The connection between the nozzle and the nozzle can be virtualized as the "umbrella handle" of the "protection umbrella." In the case of an angle of attack, the "umbrella handle" rotates counterclockwise with the center of the nozzle, so that the "umbrella handle" always flows with the incoming Parallel, so that the "umbrella tip" is in direct contact with the incoming flow, keeping the incoming flow 

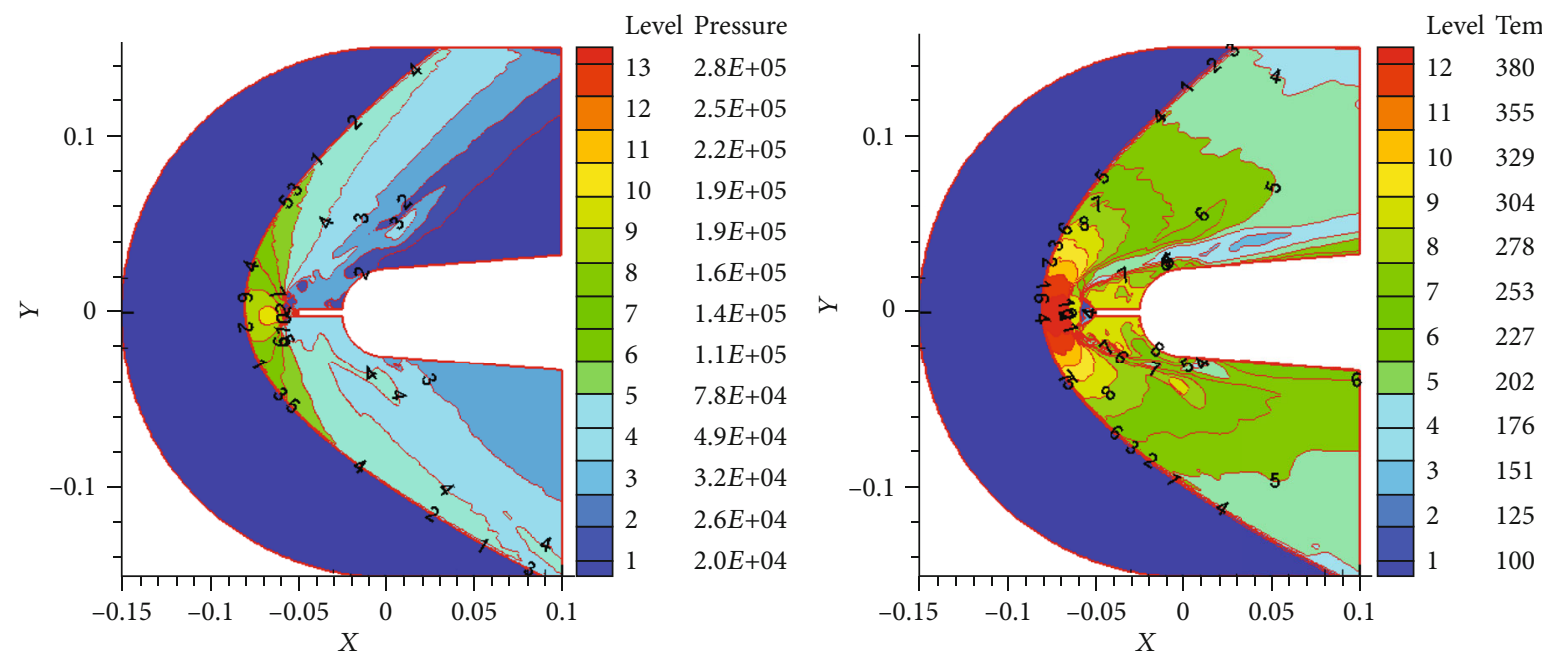

(a) $\operatorname{Pr}=0.4$ at an angle of attack of 5 degrees

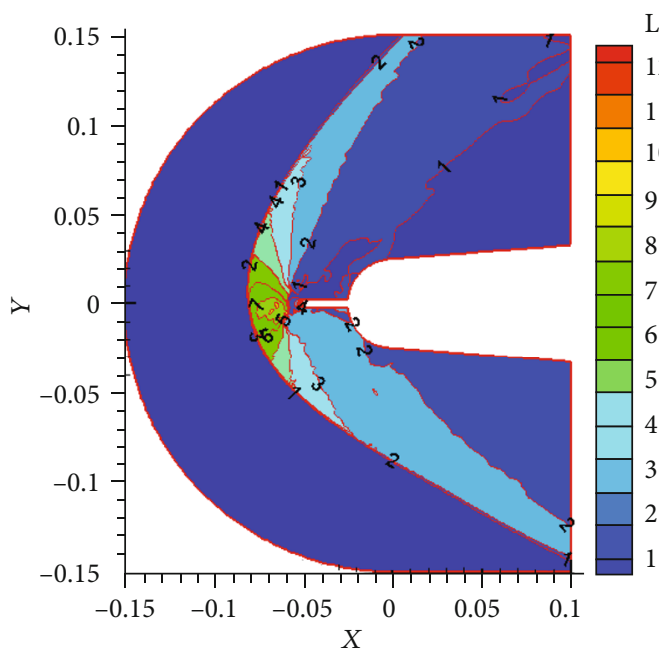

Level Pressure

$12 \quad 2.8 E+05$

$112.5 E+05$

$0 \quad 2.2 E+05$

$1.9 E+05$

$1.9 E+05$

$1.8 E+05$

$1.6 E+05$

$1.4 E+05$

$1.1 E+05$

$7.8 E+04$

$4.9 E+04$

$2.0 E+04$

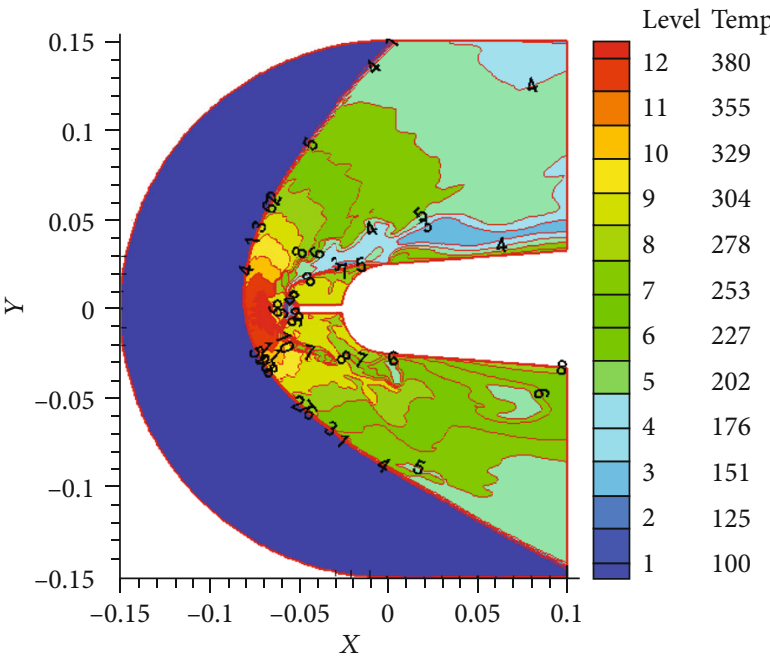

(b) $\operatorname{Pr}=0.4$ at an angle of attack of 10 degrees
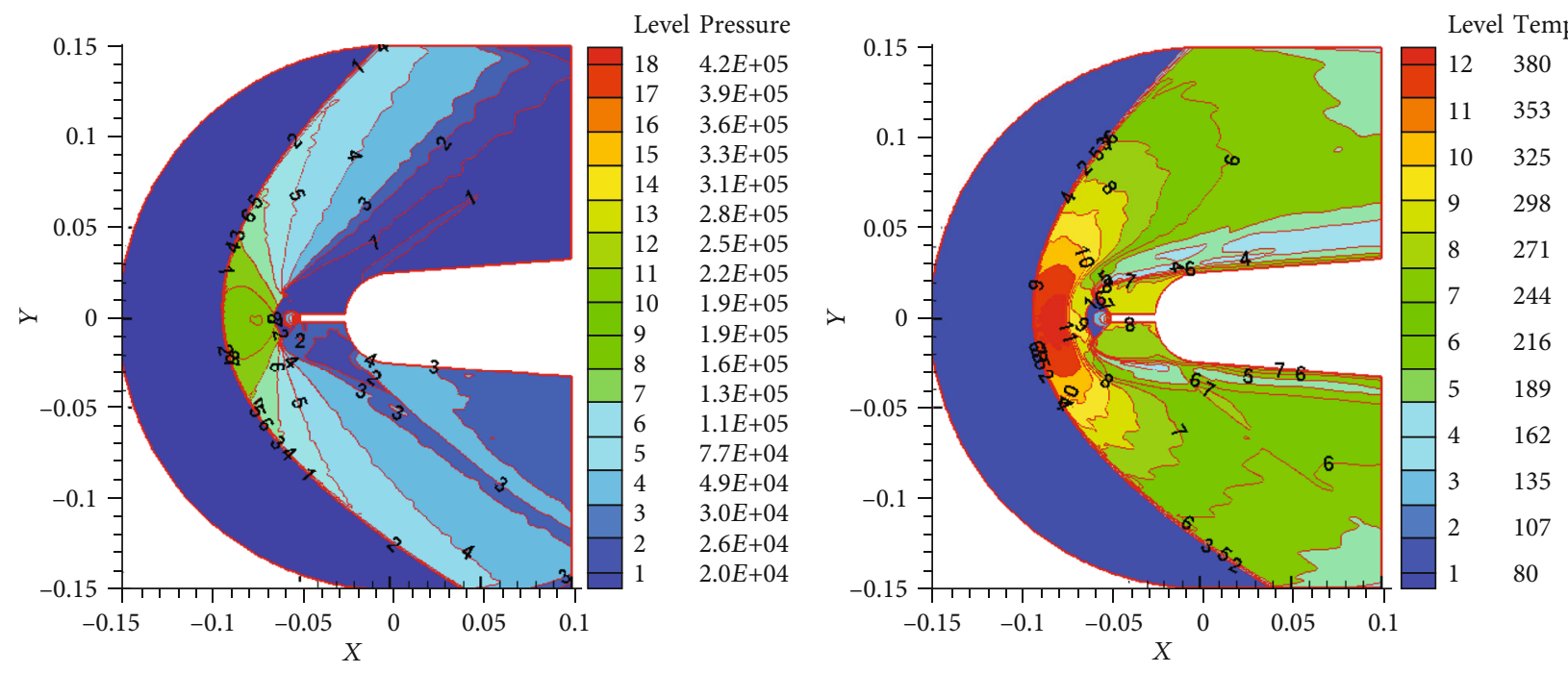

(c) $\operatorname{Pr}=0.6$ at an angle of attack of 5 degrees

FIgURE 22: Continued. 


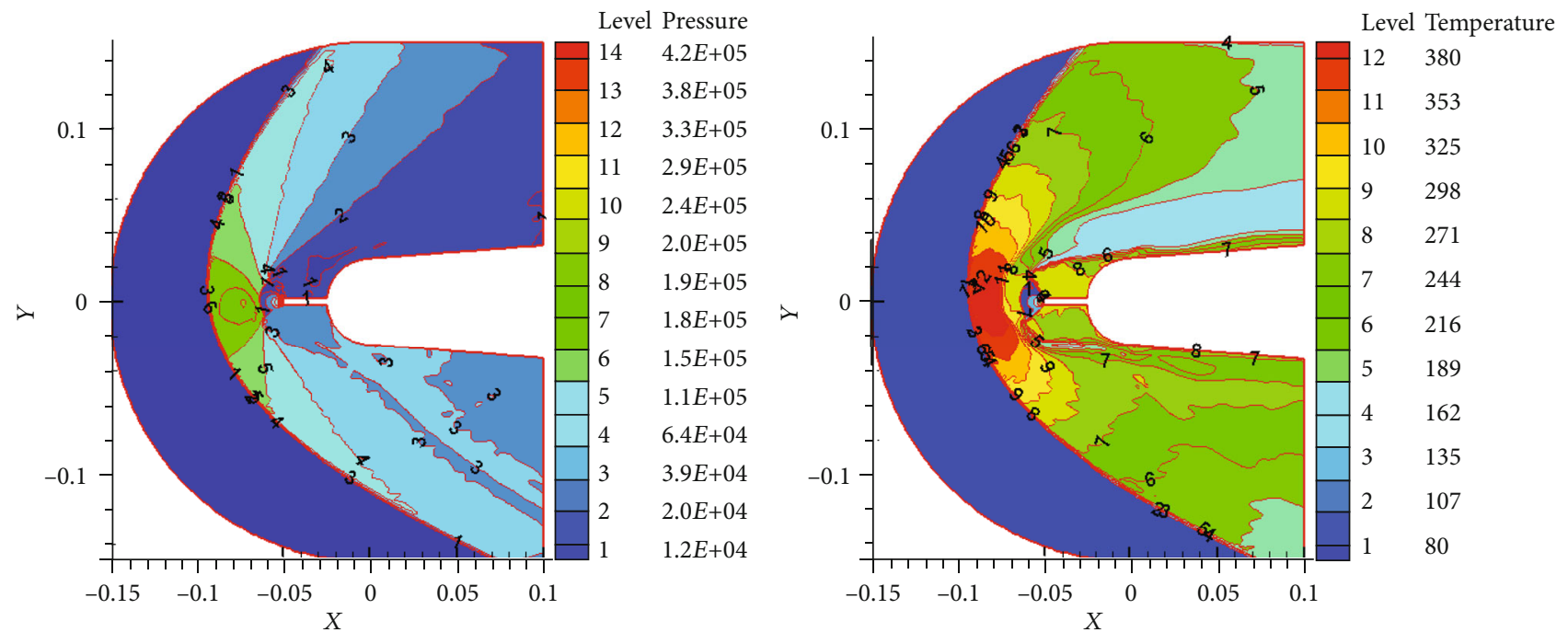

(d) $\operatorname{Pr}=0.6$ at an angle of attack of 10 degrees

FIgURE 22: Cloud/contour plots at different pressure ratios and angles of attack.

with maximum vertical flux on the "protection umbrella"; Between the "protection umbrella" and the nozzle is the recirculation zone, which plays a major role in cooling the aircraft. When the angle of attack and the incoming flow reach a certain range of values, the edge of the "protection umbrella" will intersect the aircraft ball head wall, generating reattached shock waves. At this point is the peak pressure and temperature. The combined jet can be visually compared to the "umbrella handle" that lengthens the "protection umbrella", so that the "protection umbrella" is farther away from the aircraft wall. Even if there is an angle of attack, the edge of the "protection umbrella" cannot intersect the wall, which is very good. Achieve good drag and heat reduction effect.

It is known from the numerical simulation results that the new combined jet has a better drag reduction effect than the old jet, and it is much lower than the nonjet flow, and the wall will not form any more within a certain angle of attack. Attached to the shock wave, the area after the bow forming the shock wave and the front of the aircraft head is a freestate area. The fluid moves irregularly, and the pressure, density, and temperature are low, which plays a good role in reducing the temperature of the aircraft head; The flow field of the new combined jet flow has good stability, which can form a stable flow field and a protective cover, which can reduce the impact of the angle of attack on the aircraft and facilitate the stable operation of the aircraft.

\section{Conclusions}

In this paper, after researching the development of reverse jet flow and rectifying cone technology, a combined scheme of rectifying cone and reverse jet flow is proposed, and the numerical simulation study of the combined reverse jet flow is carried out. The simulation data is analyzed in conjunction with the relevant basic theory. The following conclusions are drawn:
(1) The reverse jet can reduce the drag coefficient of the bluff body. At the same time, the stability of the two modes of the reverse jet is verified. The long mode is better than the short mode. The so-called stability of the disturbance flow field refers to the relatively stable flow parameters with slight changes, while the various parameters of the unstable flow field change periodically.

(2) When the reverse jet has an angle of attack, the drag coefficient increases with the increase of the angle of attack, but the drag coefficient with the jet is still smaller than that without the jet; When there is an angle of attack, the difference between the pressure, density, and temperature of the upper and lower walls increases as the angle of attack increases; As the angle of attack increases, the asymmetry of the flow field increases, and the flow field structure formed by the jet cannot push the high-temperature shock wave farther, so that the shear layer is attached to the wall under the action of the incoming flow, forming hot spots pose a great threat to the safety of aircraft.

(3) The combination of reverse jet and rectifier cone has better drag and heat reduction effect than the old reverse jet; The new combination method is a "protective umbrella" by the ratio of the image of the compressed shock wave formed by the jet and the free incoming flow. The reflux area between the "protective umbrella" and the nozzle plays a major role in cooling the aircraft; Within a certain range of angle of attack, no reattachment shock waves will be formed on the wall surface, and the wall surface will have a good cooling protection effect. The anti-interference performance of the combined jet is better than that of the old jet. 


\section{Data Availability}

The data used to support the findings of this study are included within the article.

\section{Conflicts of Interest}

The authors declare that there is no conflict of interests regarding the publication of this paper.

\section{Acknowledgments}

The authors wish to acknowledge the financial support by the National Science Foundation of China (Nos. 11872157, 11472086, and 11532013).

\section{References}

[1] Z. Lu, Aerodynamics, vol. 8, Beijing University of Aeronautics and Astronautics Press, Beijing, 2009.

[2] Z. Wu, G. Bing, Z. Rui, and X. Shanshu, Aerodynamics, vol. 4, Tsinghua Humanities Publishing House, Beijing, 2007.

[3] B. Wang and H. Weiguang, Hypersonic aerodynamics, Beijing: Science Press, 2014.

[4] J. D. Anderson, Fundamentals of Aerodynamics, Mc Graw-Hill Book Company, 1984.

[5] J. J. Jim, Flow separation from rods ahead of blunt noses at Mach number 2.72., Langley Research Center, 1952.

[6] C. H. E. Warren, "An experimental investigation of the effect of ejecting a coolant gas at the nose of a bluff body," Journal of Fluid Mechanics, vol. 8, no. 3, p. 400, 1960.

[7] P. J. Finley, "The flow of a jet from a body opposing a supersonic free stream," Journal of Fluid Mechanics, vol. 26, no. 2, pp. 337-368, 1966.

[8] M. Fujita, "Axisymmetric oscillations of an opposing jet from a hemispherical nose," AIAA Journal, vol. 33, no. 10, pp. 18501856, 1995.

[9] K. Hayashi and A. Shigeru, "Numerical study on aerodynamic heating reduction by oppsing jet," AIAA Journal, vol. 66, no. 1, 2005.

[10] B. Venukumar and K. P. J. REDDY, "Experimental investigation of drag reduction by forward facing high speed gas jet for a large angle blunt cone at Mach8," Sadhana, vol. 32, no. 1-2, pp. 123-131, 2007.

[11] K. Hayashi and A. Shigeru, "Effect of pressure ratio on aerodynamic heat-ing reduction due to opposing jet," in 36th AIAA Thermophysics Conference, Orlando, Florida, 2003.

[12] S. Aso, K. Hayashi, and M. Mizoguch, "A study on aerodynamic heating reduction due to opposing jet in hypersonic flow," in 40th AIAA Aerospace Sciences Meeting \& Exhibit, Reno,NV,U.S.A, 2002.

[13] V. M. Fomin, A. A. Maslov, N. D. Malmuth et al., "Influence of a Counterflow plasma jet on supersonic blunt-body pressures," AIAA Journal, vol. 40, no. 6, pp. 1170-1177, 2002.

[14] Z. Wang, H. Lu, and L. Hongshuai, "Numerical analysis of thermal protection of jet flow on the leading edge of bluff body," Journal of Astronautics, vol. 31, no. 5, pp. 1266-1271, 2010.

[15] L. Hongqing, Z. Wang, J. Chengbin, Z. Cuie, and Y. Wang, "Numerical simulation for aerodynamic heating and opposing jet thermal protection," in 2008 2nd International Symposium on Systems and Control in Aerospace and Astronautics, Shenzhen, China, 2008.

[16] C. Jin, Z. Wang, and H. Lv, "The study on oscillations of an opposing jet flow," in 2008 2nd International Symposium on Systems and Control in Aerospace and Astronautics, Shenzhen, China, 2008.

[17] Z. Chengqing and J. Yi, Gas jet dynamics, Beijing: Beijing Institute of Technology Press, 1998.

[18] H. Yanji, L. Qian, F. Juan, and D. Zhiguo, "Research progress of laser plasma drag reduction technology," Journal of Aeronautics, vol. 31, no. 1, pp. 93-101, 2010.

[19] Z. Chaoying, J. Wenying, Z. Xingwei, and L. Deng, "Numerical simulation of drag reduction of supersonic bluff body by reverse jet flow," Journal of Applied Mechanics, vol. 29, no. 2, pp. 159-164, 2012.

[20] C. Y. Zhou and W. Y. Ji, "A three-dimensional numerical investigation on drag reduction of a supersonic spherical body with an opposing jet," Proceedings of the Institution of Mechanical Engineers, Part G: Journal of Aerospace Engineering, vol. 228, no. 2, pp. 163-177, 2012.

[21] L. Ziqiang, C. Wang, P. Xie, and Z. Chaoying, "Numerical simulation of drag reduction of hypersonic plasma reverse jet," in Chinese Society of Mechanics, Zhejiang University. Proceedings of the Chinese Mechanics Conference (CCTAM 2019). Chinese Society of Mechanics, Zhejiang University: Chinese Society of Mechanics, pp. 2461-2464, 2019.

[22] X. SUN, W. HUANG, O. U. Min, R. ZHANG, and L. I. Shibin, "A survey on numerical simulations of drag and heat reduction mechanism in supersonic/hypersonic flows," Chinese Journal of Aeronautics, vol. 32, no. 4, pp. 771-784, 2019.

[23] F. Deng, F. Xie, H. Wei et al., "Application of reverse jet technology in hypersonic vehicles," Chinese Journal of Aerodynamics, vol. 35, no. 4, pp. 485-495, 2017.

[24] M. Ou, L. Yan, W. Huang, S. B. Li, and L. Q. Li, "Detailed parametric investigations on drag and heat flux reduction induced by a combinational spike and opposing jet concept in hypersonic flows," International Journal of Heat and MassTransfer, vol. 126, pp. 10-31, 2018.

[25] S. Li, W. Huang, J. Lei, and Z. Wang, "Drag and heat reduction mechanism of the porous opposing jet for variable blunt hypersonic vehicles," International Journal of Heat and Mass Transfer, vol. 126, pp. 1087-1098, 2018.

[26] W.-j. Fan, S.-b. Li, J. Zhou, W. Huang, M. Ou, and R.-r. Zhang, "Study on the drag and heat reduction performance of porous opposing jet in hypersonic flow," International Journal of Heat and Mass Transfer, vol. 139, pp. 351-361, 2019.

[27] B. X. Shen, W. Q. Liu, and L. Yin, "Drag and heat reduction efficiency research on opposing jet in supersonic flows," Aerospace Science and Technology, vol. 77, pp. 696-703, 2018.

[28] J. Huang and W.-X. Yao, "Parameter study on drag and heat reduction of a novel combinational spiked blunt body and rear opposing jet concept in hypersonic flows," International Journal of Heat and Mass Transfer, vol. 150, article 119236, 2020.

[29] Z. Wang, L. Jie, Z. Xuejun, H. Wang, and L. Zhihui, “Analysis of the influence of reverse jet flow on the drag reduction characteristics of the biconical missile," Journal of Aeronautics, pp. $1-9,2020$.

[30] H. Zhu, Y. Lin, and L. Xie, Practical course of fluid analysis and simulation, Beijing: People's Posts and Telecommunications Press, 2010. 
[31] L. Suxun, Shock wave and complex flow dominated by boundary layer, Beijing: Science Press, 2007.

[32] F. Wang, Principles and applications of CFD software for computational fluid dynamics analysis, Beijing: Tsinghua University Press, 2004.

[33] F. R. Menter, "Two-equation eddy-viscosity turbulence models for engineering applications," AIAA Journal, vol. 32, no. 8, pp. 1598-1605, 1994.

[34] M. Sheikholeslami and D. D. Ganji, "Heat transfer improvement in a double pipe heat exchanger by means of perforated turbulators," Energy Conversion and Management, vol. 127, pp. 112-123, 2016.

[35] M. B. Gerdroodbary, Y. Amini, D. D. Ganji, and M. R. Takam, "The flow feature of transverse hydrogen jet in presence of micro air jets in supersonic flow," Advances in Space Research, vol. 59, no. 5, pp. 1330-1340, 2017.

[36] A. Hassanvand, M. B. Gerdroodbary, K. Fallah, and R. Moradi, "Effect of dual micro fuel jets on mixing performance of hydrogen in cavity flameholder at supersonic flow," International Journal of Hydrogen Energy, vol. 43, no. 20, pp. 98299837, 2018.

[37] R. Zhang, W. Huang, L. Yan, L. Q. Li, S. B. Li, and R. Moradi, "Numerical investigation of drag and heat flux reduction mechanism of the pulsed counterflowing jet on a blunt body in supersonic flows," Acta Astronautica, vol. 146, pp. 123133, 2018. 